\title{
Synergistic effect of folate-conjugated polymers and 5 -fluorouracil in the treatment of colon cancer
}

\author{
Gabriela Siemiaszko ${ }^{1 *}$, Katarzyna Niemirowicz-Laskowska ${ }^{2 *}$, Karolina H. Markiewicz ${ }^{1}$, \\ Iwona Misztalewska-Turkowicz' , Ewelina Dudź', Sylwia Milewska 2,3, Paweł Misiak' , Izabela Kurowska 1,4, \\ Anna Sadowska², Halina Car $^{2}$ and Agnieszka Z. Wilczewska ${ }^{1 *}$ (1)
}

\section{${ }^{*}$ Correspondence:}

gsiemiaszko@gmail.com;

katarzyna.niemirowicz@umb. edu.pl; agawilcz@uwb.edu.pl

${ }^{1}$ Faculty of Chemistry, University of Bialystok

Ciolkowskiego $1 \mathrm{~K}$

15-245 Bialystok, Poland

${ }^{2}$ Department

of Experimental

Pharmacology, Medical

University of Bialystok,

Szpitalna 37, 15-361 Bialystok,

Poland

Full list of author information

is available at the end of the article

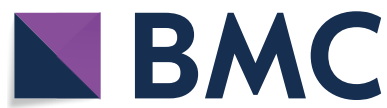

(OThe Author(s), 2021. Open Access This article is licensed under a Creative Commons Attribution 4.0 International License, which permits use, sharing, adaptation, distribution and reproduction in any medium or format, as long as you give appropriate credit to the original author(s) and the source, provide a link to the Creative Commons licence, and indicate if changes were made. The images or other third party material in this article are included in the article's Creative Commons licence, unless indicated otherwise in a credit line to the material. If material is not included in the article's Creative Commons licence and your intended use is not permitted by statutory regulation or exceeds the permitted use, you will need to obtain permission directly from the copyright holder. To view a copy of this licence, visit http:// creativecommons.org/licenses/by/4.0/. The Creative Commons Public Domain Dedication waiver (http://creativecommons.org/publi cdomain/zero/1.0/) applies to the data made available in this article, unless otherwise stated in a credit line to the data.
Results: We describe the synthesis of the diblock polymer, poly(2-hydroxyethyl acrylate)-b-poly(N-vinylcaprolactam) using RAFT/MADIX (Reversible Addition-Fragmentation chain Transfer/MAcromolecular Design by Interchange of Xanthate) controlled polymerization affording polymers with good dispersity according to SEC (Size-Exclusion Chromatography). Some post-modifications of the polymer with folic acid were then performed as evidenced by NMR (Nuclear Magnetic Resonance), UV-Vis (UltraViolet-Visible) and FT-IR (Fourier-Transform Infrared) spectroscopy, and TGA (ThermoGravimetric Analysis). The formation of stable micellar systems from polymers with and without the drug, 5-fluorouracil, was confirmed by DLS (Dynamic Light Scattering) and zeta potential measurements, and TEM (Transmission Eelectron Microscopy) imaging. Finally, the cloud point of the polymers was investigated, which turned out to be close to the temperature of the human body. Most importantly, these micellar systems have been explored as a drug delivery system against colon cancer, showing increased cytotoxicity compared to the drug alone. This effect was achieved due to the easier cellular uptake by the interaction of folic acid and its receptors on the surface of cancer cells.

Conclusions: The presented results constitute a solid foundation for the implementation of a nano-sized drug delivery system containing folic acid for practical use in the treatment of drug-resistant cancer, as well as more effective therapy with fewer side effects.

Keywords: Folic acid, Colon cancer, 5-Fluorouracil, Drug delivery system, Targeted therapy, RAFT/MADIX polymerization, Polymeric micelles, Thermoresponsive polymer 


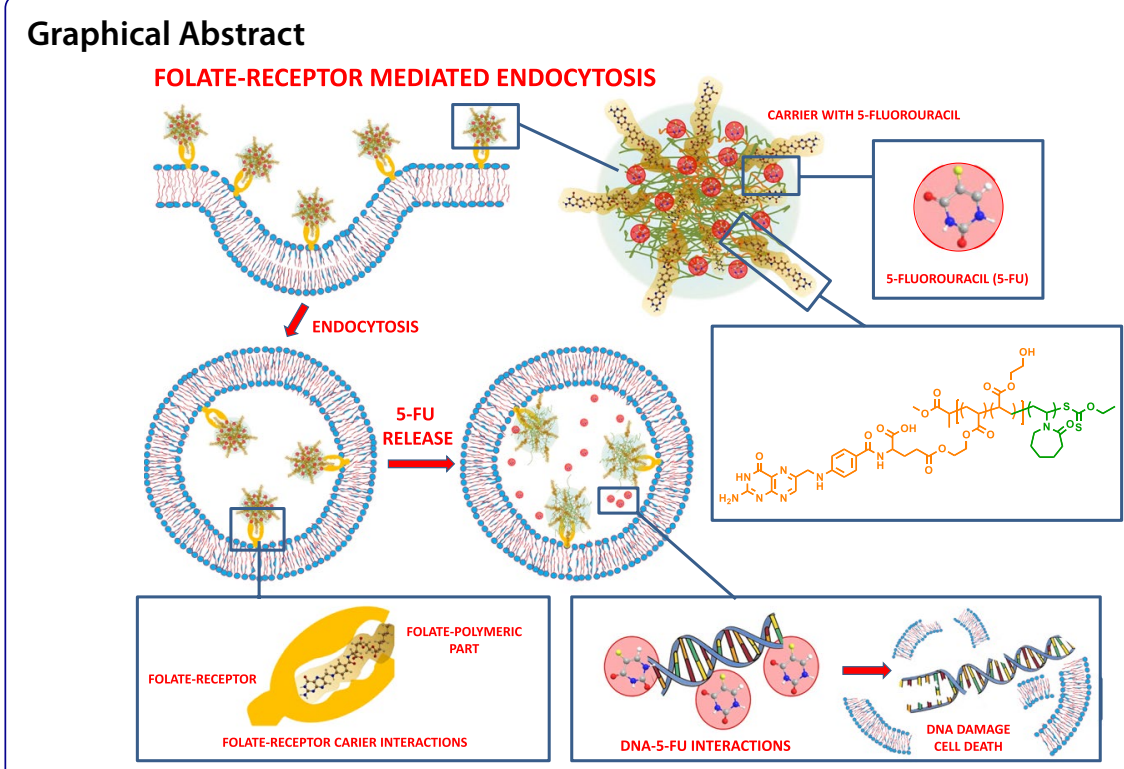

\section{Background}

Tumor-targeted drug delivery systems (TTDDS) represent a promising strategy in cancer treatment as they enable the reduction of side effects of conventional chemotherapy and increase the therapeutic efficacy. Therapies based on polymeric

nanoparticles help to overcome some physicochemical and pharmacological limitations, including poor water solubility of most anticancer drugs, non-specific distribution in the whole body, or weak biodegradability.

Furthermore, improved cancer cell penetration and prolonged drug retention at the site of action are attributed to drug delivery systems. In line with targeting therapy assumptions, the active substance or drug carrier may be attached to targeting molecules recognized by overexpressed receptors present on cancer cells. In effect, folate receptor (FR) has attracted significant attention in this area (Alvarez-Lorenzo 2014; Fernández et al. 2018; Narmani et al. 2019; Soleymani et al. 2020).

Folic acid (FA) is a vitamin involved in the synthesis of nucleic acids or DNA repair, which is bound and supplied to healthy tissue cells by a specific cell-surface glycoprotein, folate receptor. One of its subtypes, FR $\alpha$, is overexpressed in many tumor types, e.g., lung, colon, breast, ovarian, or renal cancers (Large et al. 2019; Marchetti et al. 2014; Zhao et al. 2008). It has been shown that linking folic acid to polymers enhances tumor-specific delivery of anticancer drugs having advantages of simple conjugation chemistry, low price, and lack of immunogenicity (Yu et al. 2010; Yoo et al. 2019). Various nanocarriers based on bio- and chemopolymers containing folic acid have improved the systemic performance of drugs in in vivo preclinical anticancer studies (Fernández et al. 2018).

Our previous in vivo study indicated that functionalization of aminosilane-coated magnetic nanoparticles (MNP@NH-FA) by folic acid increases particle elimination 
and protects against non-specific accumulation in organs of healthy mice. Moreover, such functionalization offers an improvement in colorectal cancer therapy due to elongated retention of MNPs and their ability to restrict tumor growth (Niemirowicz et al. 2017). However, the aforementioned magnetic structures possess some limitations, such as size-controlled synthesis, tendency to agglomeration and clusters formation. In consequence, different pharmacokinetic profiles and behavior in the organism may be observed. For example, the particles with a diameter larger than $200 \mathrm{~nm}$ are sequestered by the spleen, while structures that are smaller than $10 \mathrm{~nm}$ are removed by renal clearance (Mandal et al. 2017).

5-Fluorouracil (5-FU) is one of the first chemotherapeutic drugs reported to have anticancer activity. The drug is commonly used in the treatment of malignant tumors such as breast, pancreatic, skin, stomach, esophageal, and head and neck cancers. Moreover, 5 -FU is a pivotal element of systemic chemotherapy for colorectal cancer, both in palliative and adjuvant care (Vodenkova et al. 2020). 5-FU is a pyrimidine analog, an antimetabolite, that mechanism has been identified as an interference in the synthesis and stability of DNA and RNA of nucleic acids. The drug triggers the conversion of fluorodeoxyuridine monophosphate (FdUMP), blocking the action of thymidylate synthase (TS) and therefore inhibiting deoxythymidine monophosphate (dTMP) production required for DNA synthesis, causing cytotoxicity and apoptosis in cancer cells (Longley et al. 2003; Zhang et al. 2008). However, some limitations in the administration and efficiency of 5-FU-based chemotherapy are linked to dose-limiting toxicity to the patients and drug resistance in cancer cells. The above is reported to be related to the overexpression of factors such as TS, nuclear transcription factor (NF- $\mathrm{kB}$ ), cyclooxygenase-2 (COX-2), and insulin-like growth factor 1 receptor (IGF-1R) (Wei et al. 2018).

Recently, stimuli-responsive polymers have been extensively investigated in drug delivery. $N$-Vinylcaprolactam (NVCL) is one of the most popular temperature-responsive systems for biomedical and environmental applications due to its well-documented biocompatibility (Cortez-Lemus and Licea-Claverie 2016). Nonetheless, there are only two reported examples of folate-conjugated NVCL-based polymers. Prabaharan et al. studied the activity of 5-fluorouracil encapsulated in PNVCL- $b$-PEG-FA micelles against the mammary carcinoma cells. The cytotoxic effect was assigned to the availability of the drug for the interior of the cell due to the endocytosis process mediated by the folate receptor (Prabaharan et al. 2009). In the second case, Panja et al. described a doxorubicin delivery system based on pentaerythritol polycaprolactone- $b$ - $\operatorname{poly}(N$-vinylcaprolactam) (PE-PCL- $b$-PNVCL-FA) micelles against glioma tumor. It was proved by fluorescence studies that FA receptors promote the accumulation of folate-conjugated polymeric micelles on the C6 glioma cell line. Furthermore, the cytotoxic effect was selective against cancer cells compared to normal cells what reduces side effects of the drug-loaded vehicles (Panja et al. 2016).

Poly(2-hydroxyethyl acrylate) (PHEA) was proved to be a biocompatible material (Steinhauer et al. 2010). Double hydrophilic PHEA-based polymers are known in the literature due to their environmental friendliness and biocompatibility. An example is the synthesis of thermoresponsive polymer with $\mathrm{N}$-isopropylacrylamide (NIPAAm) that above phase transition temperature forms an amphiphilic system (Cui et al. 2016). Besides, amphiphilic block copolymers based on HEA and (2,2-dimethyl-1,3-dioxolane-4-yl)methyl acrylate 
(DMDMA) were investigated as $\mathrm{pH}$-responsive nanocarriers of hydrophobic drugs (Louage et al. 2015). However, HEA and NVCL copolymerization have not been reported so far.

In the presented study, we describe the synthesis and physicochemical characterization of a series of novel folic acid-functionalized biocompatible polymers derived from HEA and NVCL monomers via reversible addition-fragmentation chain transfer (RAFT) polymerization. The effectiveness of the esterification reaction between polymers and folic acid was investigated. Moreover, the influence of folate-conjugation extent on the cloud points, structure, and particle size was discussed. Finally, prepared carriers were tested for their biocompatibility with representative host cells (red blood cells and monocyte/macrophage cells) as well as cardiomyocyte and colon fibroblast cells. Cytotoxicity and the effectiveness of synergistic influence of these carriers and 5-fluorouracil, embedded in the polymer network due to chemical interactions, on colon cancer cells was investigated.

\section{Experimental section}

\section{Materials}

The initiator, 2,2'-azobis(2-methylpropionitrile) (AIBN, $\geq 98 \%$, Fluka) was recrystallized from methanol. Monomer, $\mathrm{N}$-vinylcaprolactam (NVCL, $>98 \%$, TCI) was recrystallized from hexane prior to use and stored in the freezer. 2-Chloropropionic acid methyl ester ( $\geq 98 \%$, Merck), 2-hydroxyethyl acrylate (96\%, Aldrich), folic acid (FA, pure, Alfa Aesar), $N, N^{\prime}$-dicyclohexylcarbodiimide (DCC, 98\%, Fluorochem), 4-dimethylaminopyridine (DMAP, $\geq 99 \%$, Aldrich), 5-fluorouracil (5-FU, Ebewe Pharma), phosphate-buffered saline (PBS, $\mathrm{pH}=7.4$, CORNING), 2-mercaptoethanol (Sigma-Aldrich), fetal bovine serum (FBS, Sigma-Aldrich), penicillin-streptomycin (Sigma-Aldrich), RPMI 1640 medium (SigmaAldrich), McCoy's 5a medium (Sigma-Aldrich), Dulbecco's modified Eagle medium (DMEM, GIBCO), MTS test (Abcam), Neutral Red (Sigma-Aldrich), Triton X-100 (SigmaAldrich) were used as received. Potassium $O$-ethyl carbonodithioate (KSCSOEt) was synthesized according to the previously reported procedure (Misiak et al. 2020). THF, acetone, hexane, EtOAc, and $\mathrm{Et}_{2} \mathrm{O}$ were purchased from Avantor Performance Materials Poland S.A., and DMSO from Chempur. THF, acetone, and DMSO were dried over activated molecular sieves $4 \AA$ and stored under argon. Deuterated solvents were purchased from Euroisotop $\left(\mathrm{CDCl}_{3}\right)$ and Armar Chemicals (DMSO- $\left.d_{6}\right)$. Silica gel $60(0.025-0.04 \mathrm{~mm})$ was purchased from Macherey-Nagel. For all experiments, glassware was dried in a laboratory oven at $120^{\circ} \mathrm{C}$.

\section{Methods}

\section{Nuclear magnetic resonance (NMR)}

${ }^{1} \mathrm{H}$ NMR spectra were recorded on Bruker Avance II 400 spectrometer operating $400 \mathrm{MHz}$. Chemical shifts $\delta$ are given in ppm, referenced to the solvent peak of $\mathrm{CDCl}_{3}$, defined at $\delta=7.26$, or DMSO $-d_{6}$, defined at $\delta=2.50$.

\section{Attenuated total reflectance Fourier-transform infrared spectroscopy (ATR-FTIR)}

ATR-FTIR spectra were made on Thermo Scientific Nicolet 6700 FTIR spectrophotometer, possessing ATR accessory. Spectra were collected in the wavenumber range from 4000 to $500 \mathrm{~cm}^{-1}$ by adding 64 scans with a resolution of $4 \mathrm{~cm}^{-1}$. 


\section{Size-exclusion chromatography (SEC)}

SEC analysis was used for the determination of number-average molecular weight $\left(M_{\mathrm{n}}\right)$ and dispersity $(\nexists)$ by using $10 \mathrm{mM} \mathrm{LiBr}$ solution in DMF as eluent at a flow rate of $1.0 \mathrm{~mL} / \mathrm{min}$ at $55{ }^{\circ} \mathrm{C}$. The preparation of the samples consisted of dissolving the polymers in the eluent (final concentration was equal to $5 \mathrm{mg} / \mathrm{mL}$ ) and filtration through a PTFE filter $(0.45 \mu \mathrm{m})$. Analysis of the samples was performed using a set of two columns, KF-804L and KF-805L Shodex (PHEA) or TSKgel Alpha-2500 and Alpha-3000 (TOSOH BIOSCIENCE) (PX-(0-4)), connected with three detectors, that is a UV detector (Prostar, Varian) set to 290 (PHEA) or $254 \mathrm{~nm}$ (PX-(0-4)), a thermostated at $35{ }^{\circ} \mathrm{C}$ refractometer (Optilab Rex, Wyatt technology), and finally a multi-angle laser light scattering detector (3 angles, Mini Dawn, Wyatt technology). The $\mathrm{dn} / \mathrm{dc}$ value of the copolymers was accepted as equal to the one of PNVCL homopolymer (0.083) (Kermagoret et al. 2013). The $\mathrm{dn} / \mathrm{dc}$ of the PHEA is equal to 0.076 (Tan et al. 2014). Polymer PX-4 was not analyzed by SEC as it is not soluble in the eluent applied.

\section{Dynamic light scattering (DLS) and $\zeta$ potential}

The colloidal stability of the polymeric systems was examined on Zetasizer Nano-ZS (Malvern Instruments, UK) with a $4 \mathrm{~mW}$ helium/neon laser $(l=633 \mathrm{~nm})$ equipped with a thermoelectric controller of temperature was used. All measurements were done with a backscatter detection system at $173^{\circ}$. The measurements of polymer samples with conc. $1 \mathrm{mg} / \mathrm{mL}$ in deionized water with or without 5 -FU (at a concentration of $50 \mu \mathrm{g} / \mathrm{mL}$ ) were completed at $25{ }^{\circ} \mathrm{C}$ after stabilization in the dark for $24 \mathrm{~h}$. The analyses were repeated five times, two extreme results were rejected, and the remaining mean of three was taken.

\section{Ultraviolet-visible spectroscopy (UV-Vis)}

UV-Vis spectra were collected using a Jasco V-670 Spectrophotometer at a wavelength range of $200-800 \mathrm{~nm}$. Polymers were examined as solutions in deionized $\mathrm{H}_{2} \mathrm{O}$ with conc. $1 \mathrm{mg} / \mathrm{mL}$ at $25{ }^{\circ} \mathrm{C}$. The exception was the polymer PX-3 for which the absorbance signal exceeded the scale of the apparatus, therefore it was tested at a concentration of $0.5 \mathrm{mg} / \mathrm{mL}$. Moreover, a standard curve of the dependence of absorbance on the concentration of folic acid in deionized $\mathrm{H}_{2} \mathrm{O}$ was made in the concentration range of $0.1-0.0025 \mathrm{mg} / \mathrm{mL}$. The absorbance was taken at $280 \mathrm{~nm}$ and general equation of the curve was determined. Based on this equation, as well as the concentrations of the polymer samples and their absorbance at $280 \mathrm{~nm}$, the FA content in the polymers was calculated.

\section{Turbidimetry}

Thermo-regulated UV-Vis spectroscopy was applied to determine the cloud points $\left(\mathrm{T}_{\mathrm{CP}}\right)$ of the samples. Solutions of polymers at a concentration of $1 \mathrm{mg} / \mathrm{mL}$ in deionized water were analyzed. To prepare solutions of polymer with the drug, 5-FU was dissolved in deionized water at a concentration of $50 \mu \mathrm{g} / \mathrm{mL}$. Next, the polymer was dissolved in this solution to obtain a polymer concentration equal to $1 \mathrm{mg} / \mathrm{mL}$ and 
analyzed. A Jasco V-670 Spectrophotometer was used to record spectra at a wavelength of $550 \mathrm{~nm}$ in the absorbance mode with a heating rate of $0.5^{\circ} \mathrm{C}$ per minute in the temperature range from 28 to $40{ }^{\circ} \mathrm{C}$. The temperature at which optical transmittance was starting to drop sharply was considered $\mathrm{T}_{\mathrm{CP}}$.

\section{Thermogravimetric analysis (TGA)}

Thermogravimetric analyses were done using a Mettler Toledo Star TGA/DSC unit. Polymeric samples weighing 2-3 mg placed in aluminum oxide crucibles were heated from 50 to $900{ }^{\circ} \mathrm{C}$. The heating rate was equal $10 \mathrm{~K} \mathrm{~min}^{-1}$, and an argon flow rate was $40 \mathrm{~mL} /$ $\min$.

\section{Transmission electron microscope}

In order to be analyzed by transmission electron microscope (TEM) plunge-freezedrying was applied to prepare samples. Briefly, solutions of polymers with a concentration of $0.1 \mathrm{mg} / \mathrm{mL}$ in deionized water without or with 5-fluorouracil (with conc. of $5 \mu \mathrm{g} \mathrm{mL}^{-1}$ ) were prepared. Next, $3 \mu \mathrm{L}$ of the sample was placed on a Holey carbon copper grid (200 mesh copper, SPI Supplies) and excess of the solution was taken away with a tissue; it was repeated twice. Treated grids were frozen with liquid nitrogen (LN2) and dried overnight on a vacuum pump. Tecnai G2 X-Twin microscope was used to take images that were taken at the accelerating $200 \mathrm{kV}$ voltage applying LN2 cryotrap for the microscope column.

\section{Freeze-drying}

Samples were freeze-dried on Christ Alpha 1-2 LDplus equipped with a double-chamber. Solutions of polymers in distilled water were frozen with LN2 followed by freezedrying under $0.013 \mathrm{mbar}$ pressure for $24 \mathrm{~h}$.

\section{Dialysis}

Dialysis was performed against DMSO or distilled water using dialysis membrane Spectra/Por ${ }^{\circledR} 6$ (MWCO 1000, surface width $18 \mathrm{~mm}$ ) at $25^{\circ} \mathrm{C}$.

\section{Synthetic procedures}

\section{Synthesis of methyl 2-((ethoxycarbonothioyl)thio)propanoate (CTA) (Taton et al. 2001)}

2-Chloropropionic acid methyl ester (1.00 equiv, $41.00 \mathrm{mmol}, 4.50 \mathrm{~mL}$ ) was dissolved in dry acetone $(32 \mathrm{~mL})$ under argon and cooled down to $0{ }^{\circ} \mathrm{C}$. KSCSOEt (1.13 equiv, $46.33 \mathrm{mmol}, 7.43 \mathrm{~g}$ ) was added portion-wise over $30 \mathrm{~min}$. The reaction proceeds at room temperature for $16 \mathrm{~h}$. Next, the reaction mixture was filtered and the solvent was evaporated. Purification by dry flash chromatography on silica gel (EtOAc/hexane, gradient from 0 to 3\%) afforded the product as a yellow liquid (7.60 g, $36.49 \mathrm{mmol}, 89 \%) .{ }^{1} \mathrm{H}$ NMR $\left(\mathrm{CDCl}_{3}, 400 \mathrm{MHz}\right): \delta 4.63\left(\mathrm{qd}, J=7.1,1.4 \mathrm{~Hz}, 2 \mathrm{H},-\mathrm{CH}_{2} \mathrm{CH}_{3}\right), 4.40(\mathrm{q}, J=7.4 \mathrm{~Hz}, 1 \mathrm{H},-$ $\left.\mathrm{CHCH}_{3}\right), 3.75\left(\mathrm{~s}, 1 \mathrm{H},-\mathrm{OCH}_{3}\right), 1.57\left(\mathrm{~d}, J=7.4 \mathrm{~Hz}, 3 \mathrm{H},-\mathrm{CHCH}_{3}\right), 1.41(\mathrm{t}, J=7.1 \mathrm{~Hz}, 3 \mathrm{H}$, $-\mathrm{CH}_{2} \mathrm{CH}_{3}$ ). 


\section{Preparation of PHEA}

Methyl 2-((ethoxycarbonothioyl)thio)propanoate (1.00 equiv, $0.50 \mathrm{mmol}, 104.15 \mathrm{mg}$ ) and 2-hydroxyethyl acrylate ( 86.12 equiv, $43.06 \mathrm{mmol}, 5.15 \mathrm{~mL}$ ) were dissolved in dry THF $(8 \mathrm{~mL})$ under argon. The mixture was immersed in an oil bath and thermostated at $70{ }^{\circ} \mathrm{C}$ while stirring. AIBN (0.10 equiv, $0.05 \mathrm{mmol}, 8.21 \mathrm{mg}$ ) as a solution in dry THF $(2 \mathrm{~mL})$ was then added, and polymerization proceeded for $2 \mathrm{~h}$ at $70{ }^{\circ} \mathrm{C}$ until monomer conversion was equal $97 \%$. After cooling, the polymer was isolated and purified by precipitation in cold $\mathrm{Et}_{2} \mathrm{O}$, collected and dried under reduced pressure, affording $4.36 \mathrm{~g}$ of the product as a colorless sticky resin. PHEA: The HEA unit number was calculated by integrating the ${ }^{1} \mathrm{H}$ NMR signals of $-\mathrm{CH}_{2} \mathrm{CH}_{3}$ and $-\mathrm{CH}_{2} \mathrm{CH}_{2} \mathrm{OH}$ and is equal to 75 (SI); $\mathrm{M}_{\mathrm{n}}=8917 \mathrm{~g} \mathrm{~mol}^{-1}$ (NMR); ${ }^{1} \mathrm{H}$ NMR (DMSO- $\left.d_{6}, 400 \mathrm{MHz}\right): \delta 4.80-4.70(\mathrm{~m}, \mathrm{OH}), 4.65(\mathrm{q}$, $\left.J=6.0 \mathrm{~Hz}, 2 \mathrm{H},-\mathrm{CH}_{2} \mathrm{CH}_{3}\right), 4.10-3.90\left(\mathrm{~m},-\mathrm{CH}_{2} \mathrm{CH}_{2} \mathrm{OH}\right), 3.60-3.50\left(\mathrm{~m},-\mathrm{CH}_{2} \mathrm{CH}_{2} \mathrm{OH}\right)$, 2.40-2.15 (m, $\left.-\mathrm{CH}_{2} \mathrm{CHC}(\mathrm{O})-\right), 1.90-1.35$ (m, $\left.-\mathrm{CH}_{2} \mathrm{CHC}(\mathrm{O})-\right)$. FTIR (neat): $3378(\mathrm{OH})$, 2950, 2880, 1724 $(\mathrm{C}=\mathrm{O}), 1448,1394,1240,1159,1073,1021,890 \mathrm{~cm}^{-1}$.

\section{Preparation of PHEA-b-PNVCL (PX-0)}

Polymer PHEA (1.00 equiv, $0.10 \mathrm{mmol}, 0.89 \mathrm{~g}$ ) and $N$-vinylcaprolactam (71.84 equiv, $7.18 \mathrm{mmol}, 1.00 \mathrm{~g})$ were dissolved in dry THF $(3.5 \mathrm{~mL})$ under argon. The mixture was immersed in an oil bath and thermostated at $70{ }^{\circ} \mathrm{C}$ while stirring. AIBN (0.4 equiv, $40.00 \mu \mathrm{mol}, 6.57 \mathrm{mg})$ as a solution in dry THF $(1.0 \mathrm{~mL})$ was added three equal portions (at the beginning, after $4 \mathrm{~h}$ and $8 \mathrm{~h}$ ). Polymerization proceeded for $24 \mathrm{~h}$ at $70{ }^{\circ} \mathrm{C}$ until monomer conversion was equal $99 \%$. The reaction mixture was concentrated and the residue dissolved in $\mathrm{CHCl}_{3}$. The polymer was isolated and purified by double precipitation in cold $\mathrm{Et}_{2} \mathrm{O}$, collected and dried under reduced pressure, affording $1.40 \mathrm{~g}$ of the product as a white powder. PHEA- $\boldsymbol{b}$-PNVCL (PX-0): ${ }^{1} \mathrm{H}$ NMR (DMSO- $d_{6}, 400 \mathrm{MHz}$ ): $\delta$ 4.80-4.70 (m, OH), 4.55-4.00 (m, $-\mathrm{CHN}(\mathrm{CO})-), 4.00-3.90\left(\mathrm{~m},-\mathrm{CH}_{2} \mathrm{CH}_{2} \mathrm{OH}\right), 3.60-$ $3.50\left(\mathrm{~m},-\mathrm{CH}_{2} \mathrm{CH}_{2} \mathrm{OH}\right), 3.25-2.80\left(\mathrm{~m},-\mathrm{CH}_{2} \mathrm{~N}(\mathrm{CO})\right), 2.45-2.10\left(\mathrm{~m},-\mathrm{CH}_{2} \mathrm{CHC}(\mathrm{O})-\right.$, $\left.-\mathrm{N}(\mathrm{CO}) \mathrm{CH}_{2}-\right), 2.05-1.00\left(\mathrm{~m},-\mathrm{CH}_{2} \mathrm{CHC}(\mathrm{O})-,-\mathrm{CH}_{2} \mathrm{CH}_{2} \mathrm{CH}_{2}-,-\mathrm{CH}_{2} \mathrm{CHN}-\right)$. IR (neat): $3360(\mathrm{OH}), 2924,2858,1724(\mathrm{C}=\mathrm{O}), 1611,1481,1443,1395,1332,1259,1158,1075$, $974,890,840 \mathrm{~cm}^{-1}$.

\section{General procedure of synthesis of P[(HEA-FA)-ran-HEA]-b-PNVCL (PX-(1-4))}

Polymer PHEA- $b$-PNVCL was freeze-dried right before the reaction. Folic acid was dissolved in dry DMSO under argon for several hours. The solution of folic acid was added to the polymer, DCC, and DMAP. The reaction proceeded for $48 \mathrm{~h}$ at room temperature under argon. Then, work-up A or B was applied. Work-up A: the reaction mixture was filtered through a cotton pad and dialyzed against DMSO for $48 \mathrm{~h}$ and subsequently against water for $96 \mathrm{~h}$, while changing water several times. The aqueous solution of the polymer was freeze-dried. Work-up B: The reaction mixture was dialyzed against DMSO for 5 days while changing DMSO several times. Subsequently, excess of water was added to the polymer solution in DMSO. It was freeze-dried twice, affording products as orange to white powders. P[(HEA-FA)-ran-HEA]- $\boldsymbol{b}$-PNVCL (PX-4): ${ }^{1} \mathrm{H}$ NMR (DMSO- $\left.d_{6}, 400 \mathrm{MHz}\right): \delta 8.64(\mathrm{~s},-\mathrm{CH}, \mathrm{FA}), 8.35-8.05$ (m, -NH, FA), $7.64(\mathrm{~d}$, $J=7.6 \mathrm{~Hz}, 2 \times-\mathrm{CH}, \mathrm{FA}), 6.92(\mathrm{~s},-\mathrm{NH}, \mathrm{FA}), 6.64(\mathrm{~d}, J=7.6 \mathrm{~Hz}, 2 \times-\mathrm{CH}, \mathrm{FA}), 4.95-4.60$ 
(m, OH), 4.60-4.10 (m, $-\mathrm{CHN}(\mathrm{CO})-), 4.10-3.80$ (m, $\left.-\mathrm{CH}_{2} \mathrm{CH}_{2} \mathrm{OFA}\right), 3.70-3.45$ (m, $\left.\mathrm{CH}_{2} \mathrm{CH}_{2} \mathrm{OFA}\right), 3.25-2.90\left(\mathrm{~m},-\mathrm{CH}_{2} \mathrm{~N}(\mathrm{CO})\right), 2.40-2.05\left(\mathrm{~m},-\mathrm{CH}_{2} \mathrm{CHC}(\mathrm{O})-,-\mathrm{N}(\mathrm{CO})\right.$ $\mathrm{CH}_{2}-$ ), 2.00-0.85 (m, $\left.-\mathrm{CH}_{2} \mathrm{CHC}(\mathrm{O})-,-\mathrm{CH}_{2} \mathrm{CH}_{2} \mathrm{CH}_{2}-,-\mathrm{CH}_{2} \mathrm{CHN}-\right)$. IR (neat): 3317 $(\mathrm{OH}), 2925,2857,1725$ (C=O), 1701, 1605, 1561, 1480, 1443, 1332, 1261, 1201, 1160, $1078,974,893,840,769 \mathrm{~cm}^{-1}$.

\section{Preparation of polymer samples for biological studies}

Polymers were dissolved in a solution of 5-fluorouracil in DMSO with conc. $2.5 \mathrm{mg} / \mathrm{mL}$, diluted with PBS solution, and vortexed. The resulting solution had a polymer concentration of $1 \mathrm{mg} / \mathrm{mL}$ and a concentration of $5-\mathrm{FU}$ of $50 \mu \mathrm{g} / \mathrm{mL}$ in 2\% DMSO/PBS medium.

\section{Biological studies}

\section{Hemolysis assay}

The hemolytic activity was tested using human red blood cells (RBCs) suspended in phosphate-buffered saline (PBS) (hematocrit $~ 5 \%$ ) with a concentration of polymeric agents 0.1 and $0.5 \mathrm{mg} / \mathrm{mL}$ with or without the presence of 5 -FU ( 5 and $25 \mu \mathrm{g} / \mathrm{mL}$ ). In brief, the RBCs were incubated with tested agents for $1 \mathrm{~h}$ at $37^{\circ} \mathrm{C}$. In the next step, relative hemoglobin concentration in supernatants after centrifugation at $2500 \mathrm{~g}$ was monitored by measuring absorbance at $540 \mathrm{~nm}$. 100\% hemolysis was taken from samples in which $1 \%$ Triton $\mathrm{X}-100$ was added to disrupt all cell membranes.

\section{Cell culture}

DLD-1, HT-29 and CaCo-2, human colorectal adenocarcinoma cell lines, as well as CCD-112CoN human colon fibroblasts were obtained from the American Type Culture Collection (ATCC). DLD-1, CaCo-2 and CCD-112 CoN were cultured in RPMI 1640 medium, line Ht-29 in McCoy's 5a medium supplemented with $10 \%$ fetal bovine serum (FBS) and $1 \%$ penicillin/streptomycin, in an incubator with $5 \% \mathrm{CO}_{2}$ at $37^{\circ} \mathrm{C}$.

The human THP-1 cell line was obtained from the ATCC. The cells were grown in RPMI 1640 medium supplemented with 10\% heat-inactivated FBS. The 1\% penicillin/ streptomycin and 2-mercaptoethanol were added at $37{ }^{\circ} \mathrm{C}$ in $5 \% \mathrm{CO}_{2}$ atmosphere so that the final concentration was $0.05 \mathrm{mM}$.

Rat embryonic cardiomyocytes $\mathrm{H} 9 \mathrm{c} 2(2-1)$ obtained from the ATCC were grown in Dulbecco's modified Eagle's Medium supplemented with 10\% FBS. 1\% penicillin/streptomycin were added, and cells were cultured at $37{ }^{\circ} \mathrm{C}$ in $5 \% \mathrm{CO}_{2}$-air.

\section{Cytotoxicity assay}

The viability of representatives of healthy (cardiomyocyte, colon fibroblast) and colorectal cancer cells were determined using a Neutral Red assay. Briefly, polymeric carriers with concentrations of 0.1 and $0.5 \mathrm{mg} / \mathrm{mL}$ were added to cells with or without the presence of 5 -FU ( 5 and $25 \mu \mathrm{g} / \mathrm{mL}$ ) and incubated $24 \mathrm{~h}$. After the exposition, the percentage of viable cells was determined by spectrophotometric methods. To achieve the above purpose, the neutral red solution, with concentration of $0.33 \%$, was added to each well and incubated. In the next step, after $2 \mathrm{~h}$ the neutral red was removed, and the cells were carefully rinsed with Neutral Red Assay Fixative. Finally, the fixative solution was 


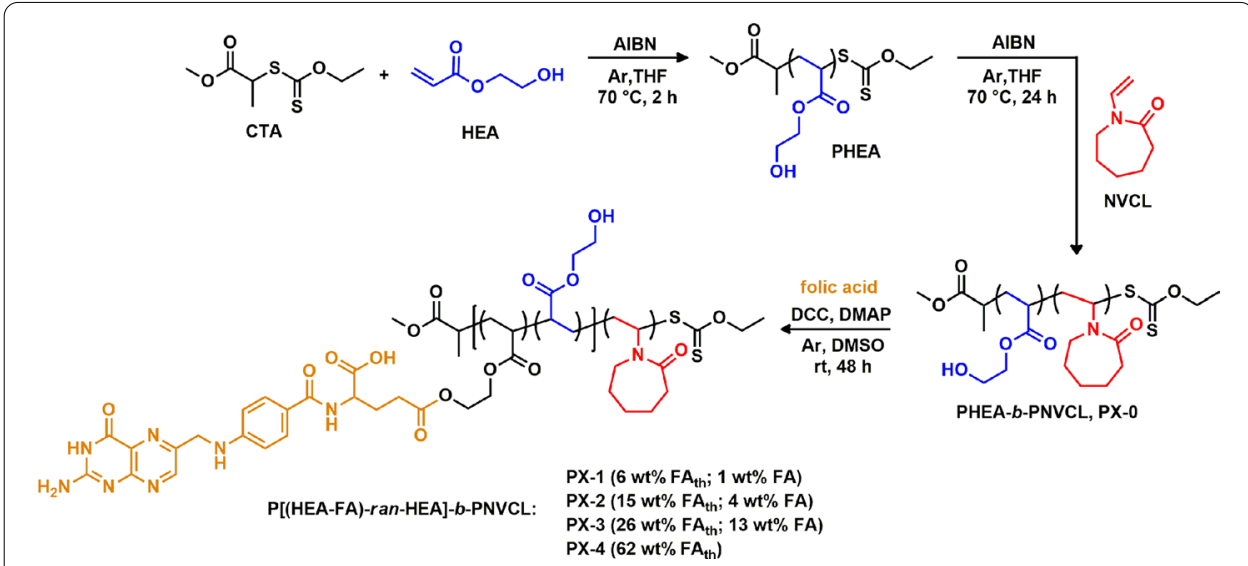

Scheme 1. Representation of synthesis of (co)polymer and post-modification process by folic acid

removed, and the dye-solubilization solution was added. The absorbance was measured at a wavelength of $540 \mathrm{~nm}$ and calculated as a percentage of control.

In another set of experiments, viability and metabolic activity of monocyte/macrophage THP-1 cells after treatment by tested polymeric carriers with or without the presence of 5-FU were assessed by the MTS test. After $24 \mathrm{~h}$ exposure, $20 \mu \mathrm{L}$ MTS reagent was added to each well. Then, the cells were incubated for $2 \mathrm{~h}$ in the dark at $37^{\circ} \mathrm{C}$ with a $5 \% \mathrm{CO}_{2}$ atmosphere. The absorbance was measured at $490 \mathrm{~nm}$ using a microplate reader and calculated as a percentage of control.

\section{Statistical analysis}

Statistical analyses were performed using Statistica 13.3 software (StatSoft Inc., Tulsa, OK, USA). The data were analyzed using standard statistical analyses, including Student's $\mathrm{t}$ test (for independent samples). $\mathrm{p}$-Values less than 0.05 were considered significant.

\section{Results and discussion}

\section{Synthesis of folate-conjugated polymers}

The folate-conjugated polymers were synthesized in three steps from simple chain transfer agent, commercially available monomers, and folic acid. First, poly(2-hydroxyethylacrylate) (PHEA) was synthesized by RAFT/MADIX polymerization from methyl 2-((ethoxycarbonothioyl)thio)propanoate (Rhodixan $\mathrm{A}_{1}$ ) chain transfer agent using the optimized procedure and easily purified by precipitation from $\mathrm{Et}_{2} \mathrm{O}$ (Scheme 1), targeting length of approximately $10,000 \mathrm{~g} \mathrm{~mol}^{-1}$. The choice of the length of this hydrophilic chain was dictated by the need to subsequently eliminate the negative effect of folic acid on target polymer water solubility. The average molecular weight obtained from ${ }^{1} \mathrm{H}$ NMR and SEC was $8920 \mathrm{~g} \mathrm{~mol}^{-1}$ and $8300 \mathrm{~g} \mathrm{~mol}^{-1}$, respectively, which is close to the assumed value. Next, a poly ( $N$-vinylcaprolactam) block was added to PHEA using an optimized RAFT procedure, and the resulting polymer was purified by simple precipitation from $\mathrm{Et}_{2} \mathrm{O}$. To obtain high monomer conversion, it was necessary to use an initiator, AIBN, in the amount of $40 \mathrm{~mol} \%$ relative to PHEA and conduct the reaction for $24 \mathrm{~h}$. 
Subsequently, quantitative conjugation of folic acid to PHEA-b-PNVCL (PX-0) using simple esterification with $N, N^{\prime}$-dicyclohexylcarbodiimide, and 4-dimethylaminopyridine in anhydrous DMSO using adapted procedures for carrier synthesis (Eliezar et al. 2015) was carried out. Following the reaction, the product solution in DMSO was dialyzed against fresh DMSO (Panja et al. 2016) until the disappearance of yellow color coming from the unreacted starting material (folic acid) followed by freeze-drying, affording the P[(HEA-FA)-ran-HEA]- $b$-PNVCL (PX-4) as an orange powder. Due to extensive dialysis, all unreacted folic acid and reaction byproducts were removed. Unfortunately, the prepared material was found to be insoluble in both water and phosphate-buffered saline.

To obtain material soluble in water, we gradually reduced the amount of folic acid with which PX-0 was coupled until we obtained a series of three water-soluble polymers, P[(HEA-FA)-ran-HEA]- $b$-PNVCL (PX-3, PX-2, PX-1), having the HEA-FA and the HEA units randomly distributed in their structure (Scheme 1; Additional file 1: Table S1). As the amount of folic acid in the esterification has been reduced, the same was performed with a solvent, which amount was strictly dependent on the folic acid because of its limited solubility in DMSO. This modification of the synthesis procedure resulted in the precipitation of an esterification byproduct, dicyclohexyl urea, which could have been filtered in reaction work-up. The time of consecutive dialysis against DMSO was shortened compared to the purification procedure of the PX-4 polymer, and the polymer solution was dialyzed against distilled water instead (Prabaharan et al. 2009).

The quantitative esterification reaction between PX-0 and folic acid has been supported by ${ }^{1} \mathrm{H}$ NMR of PX-4 (Additional file 1: Fig. S1). Signals from folic acid moiety

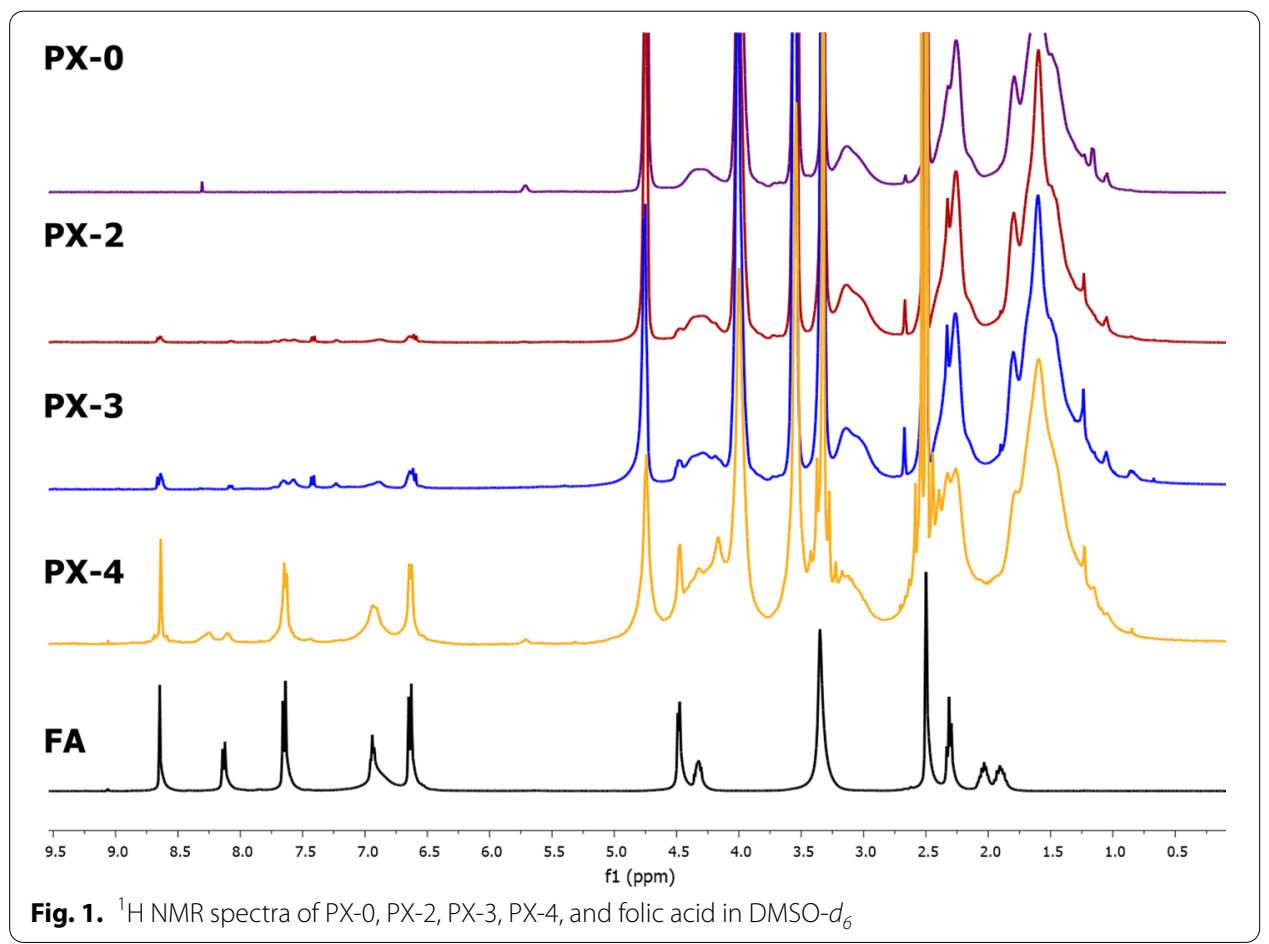


appearing in the range from 8.7 to $6.5 \mathrm{ppm}$ are visible in the NMR spectrum. They correspond to aromatic and pterin moieties as well as to amine groups. A signal from a residual number of hydroxylic groups is also present. Subsequently, investigation of folic acid conjugation in other polymers P[(HEA-FA)-ran-HEA]- $b$-PNVCL was carried out. Materials were characterized by ${ }^{1} \mathrm{H}$ NMR spectroscopy (Fig. 1), which confirmed the presence of folic acid moiety in products PX-3 and PX-2. However, despite the NMR analysis with multiple scans, the signals of folic acid in the PX-1 polymer were not revealed. This can be explained by a tiny amount of acid in the polymer chain equal to $1 \mathrm{wt} \%$.

Furthermore, FT-IR spectroscopy (Fig. 2) confirmed the presence of folic acid in the PX-4 polymer structure. Characteristic bands can be seen in the spectrum showing the enlarged region below $1900 \mathrm{~cm}^{-1}$. Signals centered at $1734 \mathrm{~cm}^{-1}, 1630 \mathrm{~cm}^{-1}$, and $1514 \mathrm{~cm}^{-1}$ are attributable to the $\mathrm{C}=\mathrm{O}$ stretching of newly formed ester bonds, $\mathrm{C}=\mathrm{O}$ stretching of secondary amide, and $\mathrm{N}-\mathrm{H}$ stretching of amide, respectively. Other bands present in the spectrum between 1480 and $1530 \mathrm{~cm}^{-1}$ can be attributed to the absorption band of the phenyl and pterin rings (Biju et al. 2018). Characterization by FT-IR spectroscopy was also carried out for samples PX-1, PX-2 and PX-3 (Additional file 1: Fig. S4). However, signals responding to folic acid or ester bond were overlapped by band characteristics of functional groups present in the PX-0 polymer.

A comparative analysis of folate conjugation was conducted by UV-Vis spectroscopy (Additional file 1: Fig. S5). UV-Vis spectra of the samples at the same temperature in deionized water confirmed the occurrence of folic acid. The absorption band at $285 \mathrm{~nm}$, which is related to the $\pi-\pi^{*}$ transition of the pterin ring of the folic acid molecule (Eliezar et al. 2015), was present in all samples, and the intensity of the bands was increased with the growing degree of polymer functionalization. Plotting the absorbance spectrum of the PX-0 polymer on the graph shows that the intensity

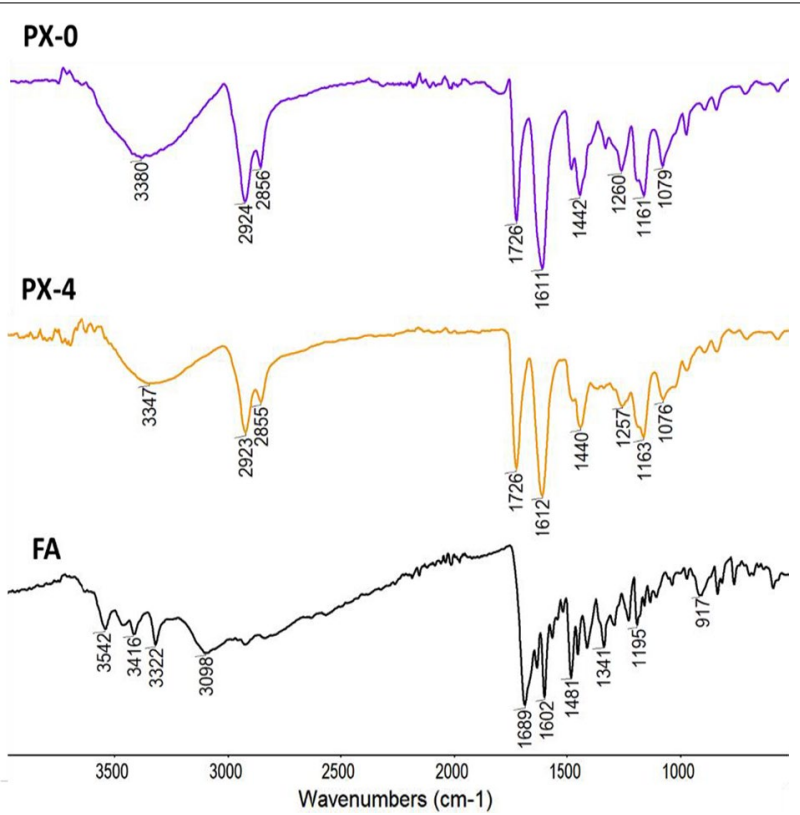

Fig. 2 FT-IR spectra of PX-0, PX-4, and folic acid 
Table 1 Summary of molecular weights of copolymers based on SEC

\begin{tabular}{llllll}
\hline Polymer & $\mathbf{w t} \% \mathbf{F A}_{\mathbf{t h}}{ }^{\mathbf{a}}$ & $\mathbf{w t} \% \mathbf{F A}^{\mathbf{b}}$ & $M_{\mathbf{n}, \mathbf{t h}}{ }^{\mathbf{c}}\left(\mathbf{g ~ m o l}^{\mathbf{- 1}}\right)$ & $M_{\mathbf{n}, \mathbf{S E C}} \mathbf{d}^{\mathbf{d}}\left(\mathbf{g ~ m o l}^{-\mathbf{1}}\right)$ & $\bigoplus^{\mathbf{d}}$ \\
\hline PHEA & 0 & - & 10,210 & 8300 & 1.97 \\
PX-0 & 0 & - & 19,810 & 16,700 & 1.56 \\
PX-1 & 6 & 1 & 21,200 & 18,000 & 1.73 \\
PX-2 & 15 & 4 & 23,300 & 22,300 & 1.83 \\
PX-3 & 26 & 13 & 26,780 & 24,200 & 2.10 \\
PX-4 & 62 & - & 51,590 & - & -
\end{tabular}

${ }^{\mathrm{a}} \mathrm{wt} \% \mathrm{FA}_{\mathrm{th}}=\left(\right.$ equiv $\left._{\mathrm{FA}} \cdot \mathrm{M}_{\mathrm{FA}} \cdot \operatorname{conv}_{\mathrm{FA}}\right): \mathrm{M}_{\mathrm{n}, \mathrm{th}}$

${ }^{\mathrm{b}}$ Calculated using the calibration curve of FA absorbance at $280 \mathrm{~nm}$ in distilled $\mathrm{H}_{2} \mathrm{O}$ vs. concentration (Additional file 1: Fig. S6)

${ }^{c} M_{n, t h}=M_{C T A}+M_{H E A} \cdot$ equiv $_{H E A} \cdot \operatorname{conv}_{H E A}+M_{N V C L} \cdot$ equiv $_{N V C L} \cdot \operatorname{conv}_{N V C L}+$ equiv $_{F A} \cdot M_{F A} \cdot \operatorname{conv}_{F A} ;$ numbers of equivalents and degrees of conversion are taken from the PHEA and PX-0 synthesis procedure and Additional file 1: Table S1; we assume that the conversion of folic acid is quantitative

${ }^{\mathrm{d}}$ Measured by SEC-RI-MALS

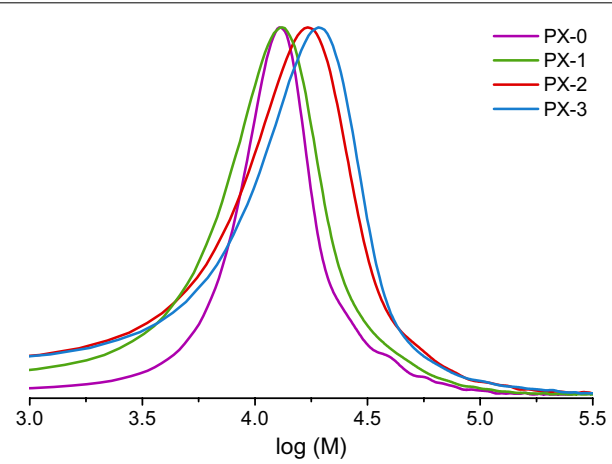

Fig. 3 Molecular mass distribution profiles of PHEA-b-PVCL copolymer before and after post-modification with folic acid

of the absorption band at $255 \mathrm{~nm}$ related to the dithiocarbonate groups (Chaturvedi et al. 2018) is low compared to the absorbance of folic acid and does not disturb the relationship shown.

The estimation of the folic acid content in the PX-1, PX-2, and PX-3 polymers was performed using the standard analytical method of the standard curve. First, the absorbance measurements of the folic acid solutions in the concentration range $0.0025-0.1 \mathrm{mg} /$ $\mathrm{mL}$ in deionized water were made at a wavelength of $280 \mathrm{~nm}$, followed by determination of the equation of the curve (Additional file 1: Fig. 6A). The results of the absorbance measurements of the polymer samples in deionized water at $280 \mathrm{~nm}$ were then used and the actual wt $\%$ of FA in the obtained carriers was calculated using the known concentration of the samples ( 1 or $0.5 \mathrm{mg} / \mathrm{mL}$ ) (Table 1; Additional file 1: Fig. 6B). As could be expected, the values determined are lower than the calculated theoretical wt\% FA in polymers, reaching a maximum amount of $13 \mathrm{wt} \%$ in case of PX-3. It should be emphasized that these values do not correspond to the efficiency of the esterification reaction, since after the esterification intensive dialysis against DMSO and water were performed, and therefore some of the FA-containing polymer chains were removed. The analysis was not performed for the PX-4 sample due to its insolubility in water. 
Number-average molecular weights $\left(M_{\mathrm{n}}\right)$ and dispersity indexes $(\nexists)$ of the PX-0, PX-1, PX-2, PX-3 products were determined by size-exclusion chromatography (SEC) (Table 1). For the starting material (PX-0), the molecular mass obtained from SEC $\left(16,700 \mathrm{~g} \mathrm{~mol}^{-1}\right)$ is close to the theoretical one $\left(19,810 \mathrm{~g} \mathrm{~mol}^{-1}\right)$. Taking into account the molecular weight of PHEA calculated from SEC $\left(8300 \mathrm{~g} \mathrm{~mol}^{-1}\right)$, the length of PNVCL block is $8400 \mathrm{~g} \mathrm{~mol}^{-1}$. All the polymers show narrow molar mass distribution, however, additional branch representing higher molecular masses can be observed in molecular mass distribution profiles and SEC-RI traces (Fig. 3, Additional file 1: Fig. S7A). Even though branching was observed, the dispersity index for PX-0 is relatively good (for polymers containing PVCL $Ð \leq 1.5$ is a good result) (Beija et al. 2011; Zhao et al. 2015; Siirilä et al. 2019).

After functionalization of PHEA- $b$-PNVCL chains with various quantities of FA, $M_{\mathrm{n}}$, and $Ð$ increase (Table 1). An increase in dispersity indexes of samples PX-1, PX-2, and PX-3 can be explained by the random presence of FA in the polymeric chains. The main result which indicates that the modification with FA occurred is UV detection response, which grows along with FA concentration (Additional file 1: Fig. S7B).

The TGA/DTG curves of folic acid, PHEA- $b$-PNVCL, and folate-conjugated polymers are presented in Additional file 1: Fig. S8. Folic acid decomposes in a wide temperature range $\left(100-800{ }^{\circ} \mathrm{C}\right)$ in four overlapping stages; at the temperature of $800{ }^{\circ} \mathrm{C}$, a total weight loss of $73 \%$ is observed (Vora et al. 2002). The main decomposition of unmodified polymer (PX-0) and folate-conjugated polymer (PX-(1-4)) occurred in the temperature range between 300 and $450^{\circ} \mathrm{C}$, which is typical of PHEA and PNVCL depolymerization (Vargün and Usanmaz 2005). Non-functionalized polymer (PX-0), and polymers containing the smallest amounts of FA (PX-1 and PX-2) have similar thermal degradation profiles and decompose almost completely in the applied temperature range. However, in the cases of PX-3 and PX-4, the observed weight loss at $800{ }^{\circ} \mathrm{C}$ is equal to 90 and $77 \%$, respectively. The residues are presumably related to the presence of substantial quantities of folic acid, which does not decompose totally in the applied temperature range.

\section{Hydrodynamic diameter and colloidal stability measurements}

The synthesized water-soluble polymers were investigated by DLS with a concentration of $1 \mathrm{mg} / \mathrm{mL}$ at $25^{\circ} \mathrm{C}$ after stabilizing for $24 \mathrm{~h}$ in the dark (Fig. 4A). The hydrodynamic diameters of PX-0 and PX-1 polymers were low, equal to around $5-8 \mathrm{~nm}$ at $25^{\circ} \mathrm{C}$. This
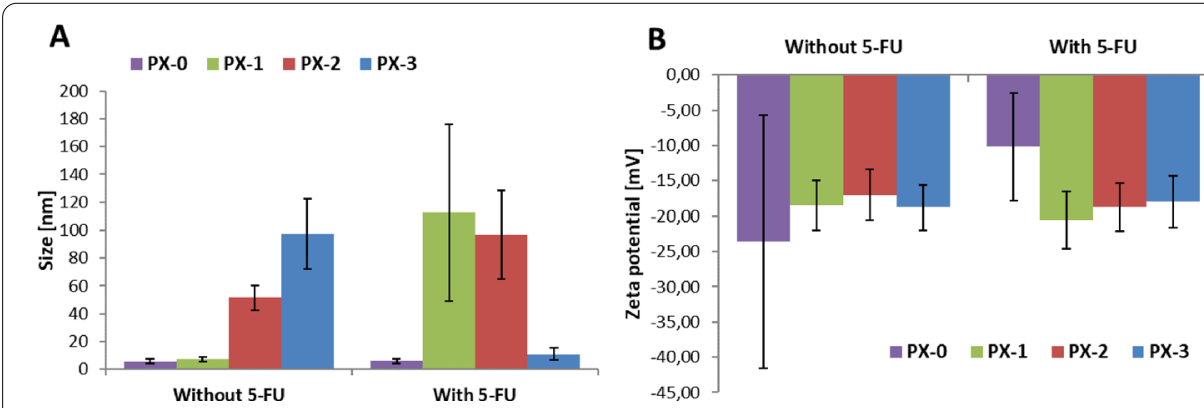

Fig. 4 A DLS data (size by number) and $\mathbf{B}$ zeta potential measurements of polymer samples with conc $1 \mathrm{mg} / \mathrm{mL}$ in deionized water at $25^{\circ} \mathrm{C}$ after stabilization in the dark for $24 \mathrm{~h}$ 
is typical of double hydrophilic polymers that are in the form of unimers in an aqueous solution (Cui et al. 2016; Jiang et al. 2013a). The binding of folic acid to some hydroxyl groups of PX-0 reduced the hydrophilicity of the PHEA segment. Hence, micellar structures having a PNVCL crown and an interior composed of P[(HEA-FA)-ran-HEA] domains were formed from polymers PX-2 and PX-3. Micelles sizes range from around $50 \mathrm{~nm}$ to $100 \mathrm{~nm}$. As shown in the graph, the size of the structures increases with folic acid content. Subsequently, the zeta potential of polymers was measured after a $24 \mathrm{~h}$ stabilization in the dark (Fig. 4B). Its negative values, ranging from -17 to $-24 \mathrm{mV}$, confirm the sufficient stability of the tested unimers and micelles in the aqueous medium (Panja et al. 2016).

Afterward, the polymers were dissolved in water in the presence of the drug (in the amount of $50 \mu \mathrm{g} 5$-FU per $1 \mathrm{mg}$ of polymer) and analyzed by DLS (Fig. 4A). The presence of the drug did not affect the hydrodynamic diameter of PHEA- $b$-PNVCL polymer. Interestingly, we noticed the inverse relationship between the size of structures formed in the presence of drug from folate-conjugated polymers and the content of folic acid. This may indicate that 5-fluorouracil decreases the amphiphilic nature of polymer PX-3 by reducing the hydrophobicity of the folic acid by the $\pi-\pi$ stacking with 5 -FU (Hazrati and Hadipour 2016). On the other hand, when there is less folic acid in the polymer, hydrogen bonds between the amide groups of the PNVCL chain and 5-FU may be dominant, which results in a decrease in the hydrophilicity of the PNVCL blocks and their presence in the middle of micellar structures having a crown made of P[(HEA-FA)-ranHEA] domains (PX-1 and PX-2). Moreover, as shown by zeta potential analysis (Fig. 4B), all of the polymers analyzed are stable in an aqueous solution of 5-FU.

TEM imaging was performed to analyze the morphology of structures formed from polymer samples prepared by plunge-freeze-drying of their aqueous solutions (Fig. 5). Folic acid conjugated polymers were selected for analysis. As one can see in the images with larger magnification (bottom panel), the polymers organize themselves into structures with a round shape and smooth edges. Furthermore, the images which were taken with lower magnification (upper panel) show the formation of agglomerates of irregular

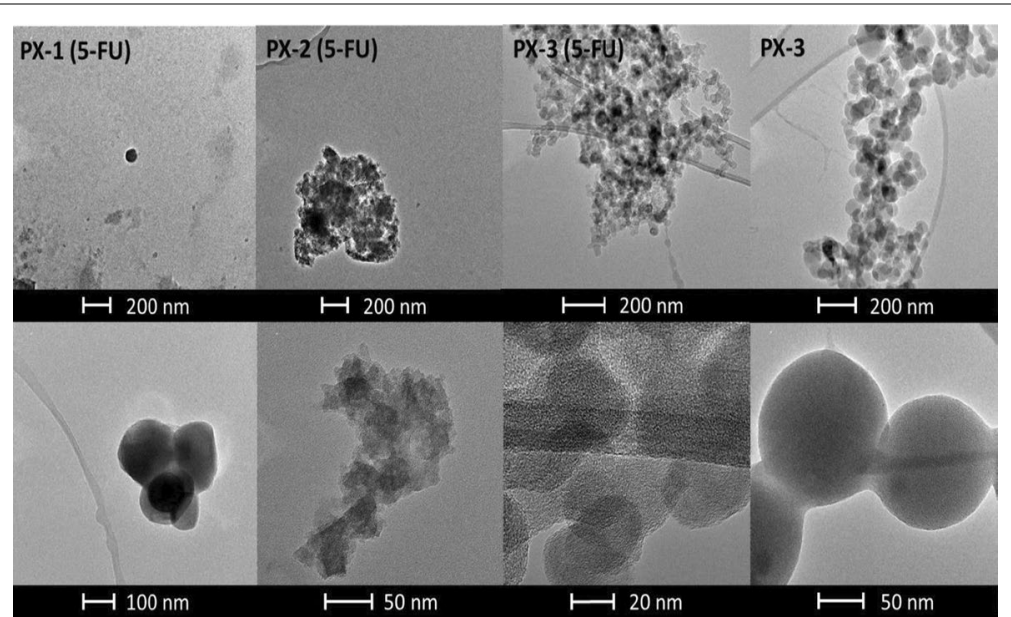

Fig. 5 TEM images of micelles of folate-conjugated polymers P[(HEA-FA)-ran-HEA]-b-PNVCL (PX-1, PX-2, PX-3) with 5-fluorouracil, and bare polymer PX-3, with different magnifications 
Table 2 Turbidimetry data for PHEA-b-PNVCL and P[(HEA-FA)-ran-HEA]- $b$-PNVCL polymers

\begin{tabular}{llc}
\hline Polymer $^{\mathbf{a}}$ & \multicolumn{2}{l}{$T_{\mathbf{C P}}\left[{ }^{\circ} \mathbf{C}\right]$} \\
\cline { 2 - 3 } & Without 5-FU & With 5-FU \\
\hline PHEA-b-PNVCL, PX-0 & $32.5 \pm 0.5$ & $34.5 \pm 0.5$ \\
P[(HEA-FA)-ran-HEA]-b-PNVCL, PX-1 & $31.0 \pm 0.5$ & $34.5 \pm 0.5$ \\
P[(HEA-FA)-ran-HEA]-b-PNVCL, PX-2 & $31.0 \pm 0.5$ & $34.5 \pm 0.5$ \\
P[(HEA-FA)-ran-HEA]-b-PNVCL, PX-3 & $31.0 \pm 0.5$ & $36.0 \pm 0.5$ \\
\hline
\end{tabular}

a Solutions with concentration of $1 \mathrm{mg} / \mathrm{mL}$ of polymer and $50 \mu \mathrm{g} / \mathrm{mL}$ of 5-FU (if applied) in deionized water
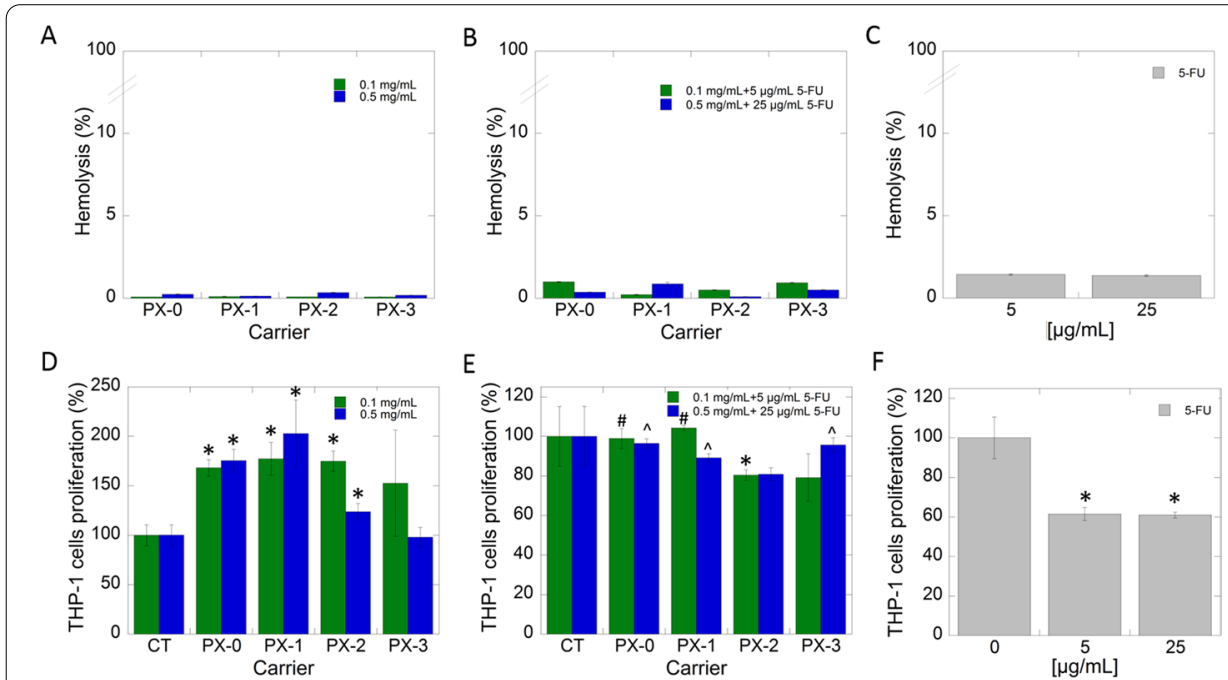

Fig. 6 Hemolytic activity and viability of monocytic THP-1 cells after addition of folate-conjugated polymers $(\mathbf{A}$ and $\mathbf{D})$, folate-conjugated polymers with 5-FU (B and $\mathbf{E})$, and 5-FU (C and $\mathbf{F})$. Statistical significance for the folate-conjugated polymers without or with 5 -FU or 5 -FU vs control was marked with $(*)$; comparison of 5-FU concentration at free vs encapsulated form 5 -FU $5 \mu \mathrm{g} / \mathrm{mL}$ vs $0.1 \mathrm{mg} / \mathrm{mL}+5-\mathrm{FU} 5 \mu \mathrm{g} / \mathrm{mL}$ marked with (\#) and $5-\mathrm{FU} 25 \mu \mathrm{g} / \mathrm{mL}$ vs $0.5 \mathrm{mg} / \mathrm{mL}+5-\mathrm{FU} 25 \mu \mathrm{g} / \mathrm{mL}$ marked with $(\wedge), p \leq 0.05$. The data presented constitute average results from three measurements \pm SD

shapes. In the presence of 5-FU, the polymer with the highest content of folic acid (PX3) forms structures with a size of around $30 \mathrm{~nm}$, and the remaining polymers (PX-2, PX-1) have larger sizes the smallest of which are equal to approximately $120-140 \mathrm{~nm}$. Furthermore, in an image of the PX-3 polymer in the absence of the drug, structures of around $120 \mathrm{~nm}$ in size can be observed. Therefore, it can be said that for the PX(1-3) polymers in the presence of 5-FU, the diameter of the structures formed increases inversely to the content of folic acid. In turn, the sample of PX-3 without the 5-FU is characterized by the formation of larger structures compared to PX-3 which contains the drug. These trends are the same as those observed for DLS results.

\section{Thermoresponsive characteristic}

The cloud point temperature $\left(\mathrm{T}_{\mathrm{CP}}\right)$ of copolymers was determined by the turbidimetric method using water solutions of polymers with a concentration equal to $1 \mathrm{mg} / \mathrm{mL}$ (Table 2). We know that both pure PNVCL (Cortez-Lemus and Licea-Claverie 2016) and its diblock derivatives (Prabaharan et al. 2009) have LCST, therefore we expected 
a phase transition due to the heating of the sample. The optical transmittance change at $550 \mathrm{~nm}$ in the temperature range from 28 to $40^{\circ} \mathrm{C}$ was monitored. The phase transition temperature of the PX-0 was found to be equal to $32.5{ }^{\circ} \mathrm{C}$. Folate-conjugated polymers, PX-(1-3), exhibited slightly lower $\mathrm{T}_{\mathrm{CP}}$ equal to around $31^{\circ} \mathrm{C}$. This is in line with the literature where the inverse relationship between the amount of folic acid in the polymer chain and the value of the phase transition temperature was observed for PNVCL-based materials (Panja et al. 2016).

Afterward, $T_{\mathrm{CP}}$ of polymers dissolved in an aqueous 5-fluorouracil solution (in the amount of $50 \mu \mathrm{g} 5$-FU per $1 \mathrm{mg}$ of polymer) was studied. From the results, one can generally see an increase in the phase transition points for each of the polymers due to the addition of the drug. It can be explained by the formation of hydrogen bonds between drug and PNVCL chain amide groups. Interestingly, the observed increase in Tcp is highest for the polymer with the utmost amount of folic acid, PX-3.

Above the phase transition temperature, partial displacement of water from the polymer weakens hydrogen bonds between hydrophilic components, and interactions between hydrophobic segments become dominant (Jiang et al. 2013b). We assume that all prepared polymers are amphiphilic after this phase transition and can create polymeric micelles in an aqueous solution.

\section{Biological studies}

Recently published GLOBOCAN reports indicated that colorectal cancer (CRC) is a disease that is associated with high morbidity and mortality rates (Bray et al. 2018). 5-Fluorouracil (5-FU) is the first-line recommended anticancer agent used in the treatment of colorectal cancer. Unfortunately, due to the rising rate of drug resistance phenomena in cancer cells, the effectiveness of therapy is highly reduced and restricted. Important is the fact, that 5 -FU resistance might by associated with impaired drug uptake, target alterations, resistance to apoptosis and activation of DNA repair pathways (Zheng 2017). Moreover, the most common side effects of 5-FU during anticancer therapy are myelosuppression, cardiotoxicity, diarrhea, dermatitis, and mucositis. Besides the aforementioned side effects, there are also reports showing that 5-FU therapy might be associated with the induction of acute intravascular hemolysis (Sandvei et al. 1987). In effect, searching for new approach in the CRC patients treatment that will provide increased sensitivity of cancer cells to chemotherapeutic agents and reduce non-specific interaction with the healthy tissue is a major challenge for medicine.

In the first step of the study, an evaluation of hemocompatibility of the synthesized carriers with or without the presence of 5-FU in comparison to 5-FU in free form has been performed (Fig. 6). Results indicate that incubation of carriers themselves and when 5-FU was incorporated, did not disrupt the membrane of RBC cells (Fig. 6A, B). Percentage of hemolytic cells at the level of $\sim 1 \%$ classifies drug vehicles as non-hemolytic material. However, in the case of 5-FU applied in free form, hemolysis around 1.5\% has been detected (Fig. 6C). Based on classification published by Totea et al., material resulting in hemolysis between 2 and $5 \%$ is classified to the second group as slightly hemolytic (Totea et al. 2014). In effect, the application of the examined carriers for 5-FU delivery might protect from the incidence of acute immune hemolytic anemia (AIHA). 
As mentioned above, the most frequent anticancer therapy complication is the impact of applied agents in depleting hematopoietic cells, including monocytic germ leading to monocytopenia (Ouyang et al. 2018). In a recent review, Patysheva et al. indicated that the response of monocyte/macrophage cells to treatment by cytostatic agents is probably realized due to a change in the function of these cells. Moreover, the authors suggest that chemotherapeutic treatment might also affect the functional polarization of monocytes and macrophages and modulate their epigenetic profile and activate recruitment from the bone marrow and migration to the tumor site (Patysheva et al. 2019). In agreement with other studies, $~ 40 \%$ depletion of the ability of monocyte/macrophage cells to proliferate after treatment by 5 -FU has been observed (Fig. 6F) (VanderVeen et al. 2020; Jeong et al. 2019; Farhat et al. 2014). Interestingly, after the addition of our polymeric systems to the THP-1 cells, increased proliferation was noted (Fig. 6D). The observed effect might be related to cell proliferation or also to a higher metabolic activity of cells in the presence of polymer. The aforementioned results are supported by study performed by Sala et al. The authors investigated the compatibility of PNVCL polymers at concentrations 0.01 and $1 \mathrm{mg} / \mathrm{mL}$ to mesenchymal stem cells (MSCs) and indicated that each of these conditions showed a significant increase in the cell viability -in the case of PNVCL with high molecular weight proliferation/viability around $180 \%$ has been observed (Sala et al. 2017). Most important is that the cytotoxic effect of 5 -FU is balanced by the positive impact of the carriers. In effect, the treatment of tested cells by synthesized PNVCL derivatives after incorporating 5-FU does not considerably affect their function and metabolic activity. In the worst case, $20 \%$ depletion of THP-1 cell proliferation has been noted (Fig. 6E). For example, in the case of 5-FU with PX-3 carrier with the greatest content of folic acid moiety, more than $90 \%$ cell viability has been detected. Those as mentioned above, might suggest the protective role of FA decorated carriers against the toxic effect of chemotherapeutic agents.

It is established that after anthracyclines, 5-FU is the second most common chemotherapeutic drug associated with cardiotoxicity (Sara et al. 2018). The cardiotoxicity related to 5 -FU administration is manifested by chest pain, acute coronary syndrome/ myocardial infarction, or death (Camaro et al. 2009; Lestuzzi et al. 2014). It is supposed that direct cellular damage and ischemia are two potential mechanisms by which 5-FU may lead to cardiotoxicity. For this reason, our systems were evaluated in terms of cytotoxicity against embryonic rat cardiomyocytes $\mathrm{H} 9 \mathrm{C} 2$ line, which is a subclonal line of the original clonal cell line derived from embryonic BD1X rat heart tissue by Kimes and Brandt (Witek et al. 2016). This line is commonly used in numerous in vitro studies, in particular, for cardiotoxicity analyses of new, mainly anticancer drugs.

Results presented in Fig. 7A indicated that the examined polymeric systems applied with a concentration of $0.1 \mathrm{mg} / \mathrm{mL}$ caused increased viability of cardiomyocytes with an increase in the number of folic acid molecules in the polymer structure $(90 \%$ for PX-1 to $120 \%$ for PX-3). The same trend was observed after the treatment of tested cells by a drug-containing polymer (Fig. 7B). However, treatment of cells by 5 -FU in free form causes more than $65 \%$ depletion of cell viability (Fig. 7C). Therefore, elimination of the cytotoxic effect of a representative of fluoropyrimidines after incorporation into polymer structures was noted. 

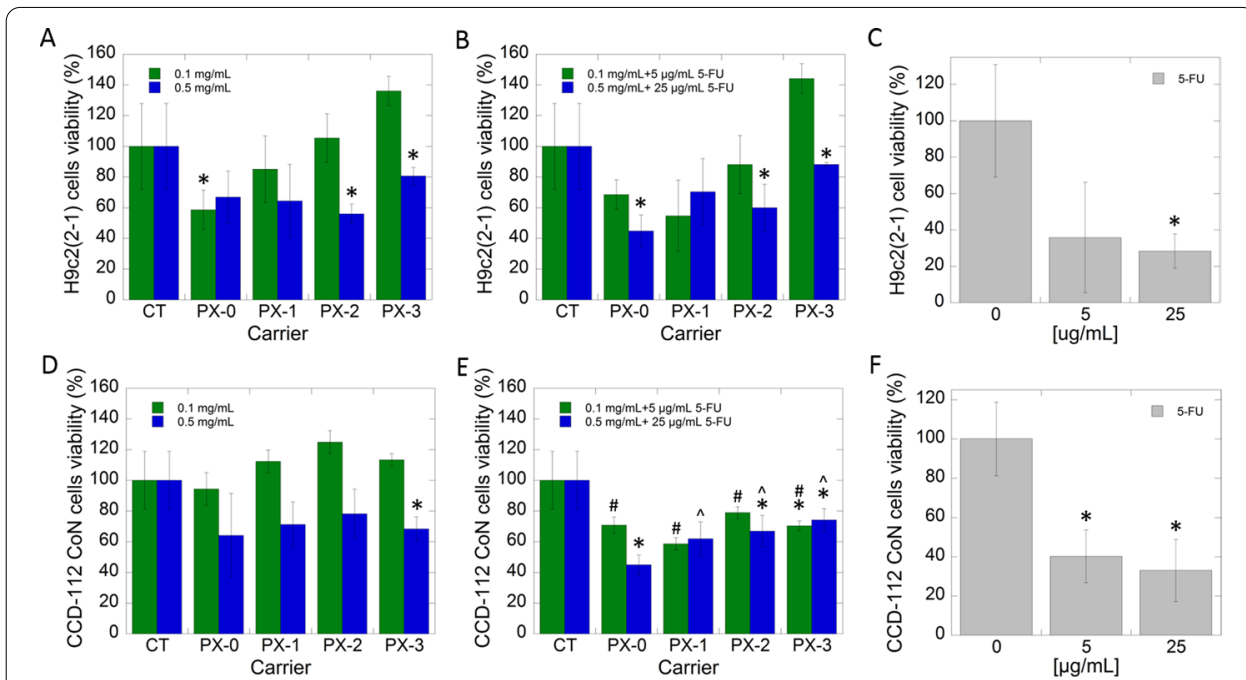

Fig. 7 Compatibility of folate-conjugated polymers with or without 5-FU against representatives of normal cells. Viability of cardiomyocyte cells and colon fibroblast cells after addition of folate-conjugated polymers (A and $\mathbf{D})$, folate-conjugated polymers with 5-FU (B and E) and 5-FU (C and $\mathbf{F})$. Statistical significance for the folate-conjugated polymers without or with 5-FU or 5-FU vs. control was marked with (*); comparison of 5-FU concentration at free vs encapsulated form 5 -FU $5 \mu \mathrm{g} / \mathrm{mL}$ vs $0.1 \mathrm{mg} / \mathrm{mL}+5-\mathrm{FU} 5 \mu \mathrm{g} / \mathrm{mL}$ marked with (\#) and $5-\mathrm{FU} 25 \mu \mathrm{g} / \mathrm{mL}$ vs $0.5 \mathrm{mg} / \mathrm{mL}+5-\mathrm{FU} 25 \mu \mathrm{g} / \mathrm{mL}$ marked with $(\wedge), p \leq 0.05$. The data presented constitute average results from three measurements \pm SD

It is known that more than $80 \%$ of patients who have received cancer treatment by using 5-FU developed gastrointestinal mucositis (Sonis et al. 2004). It is the most frequently occurring toxicity in cancer chemotherapy, and that is associated with intense pain and high-risk factors for hematosepsis with neutropenia and malnutrition. In effect, it should be emphasized that induction of gastrointestinal mucositis, including inflammation of the small intestine, leads to problems that affect the prognosis of patients. The study performed by Soares et al. indicated that rat animal models treated with 5-FU showed reduced gastrointestinal villi length, increased crypt depth, elevated apoptosis index, and increased inflammatory mediator levels (Soares et al. 2008). Therefore, in this study, the compatibility of tested polymeric carries with/or without the presence of 5-FU and 5-FU in free form on colon fibroblast cells has been investigated (Fig. 7D-F). To date, different strategies have been engaged to ameliorate 5-FU-induced gastrointestinal mucositis, mainly including the application of products from the natural origin as adjuvant of therapy (Zhang et al. 2018). In our study, we use FA-modified polymeric carries as a delivery system of 5-FU. Results showed that treatment of cells by 5-FU applied in free form caused a significant reduction of viable cells up to $40 \%$ and $30 \%$ after the addition of 5 -FU at concentrations 5 and $25 \mu \mathrm{g} / \mathrm{mL}$, respectively. It should be emphasized that using synthesized carriers with FA moiety resulted in significant decrease of 5-FU cytotoxicity and classified the percentage of viable cells at about 70\% (Fig. 7E). Interesting is the fact that with increasing FA-content, the viability of colon fibroblast cells was steadily increasing. This might suggest that presence of FA could be helpful to reduce the side and toxic effects of cytostatic treatment against normal cells.

To select an appropriate receptor for targeted drug delivery several criteria must be considered, where the most important is a significantly higher expression of the receptor 
of interest on cancerous tissue relative to normal cells (Srinivasarao et al. 2015). In cells, folates (FA) are needed for DNA synthesis and repair, which makes them an integral factor for the proper survival of normal cells. In the case of the tumor tissues, FA is required to sustain their uncontrolled, rapid, and offensive proliferation (Fernández et al. 2018). In effect, FA as a selective targeting ligand, possess several important features such as (1) high affinity to its target, folate receptors (FRs), even after conjugation with other agents; (2) undetectable or low expression of its receptors on host cells, despite its overexpression on cancer cells; (3) facility of chemical conjugation with a variety of therapeutic platform or agents (Yi 2016). In the next step of the study, we investigated the ability of synthesized polymeric systems to overcome the resistance of CRC cells to 5-FU. For this purpose, three cell lines which have overexpressed the folate receptor on their surface (Fernández et al. 2018; Srinivasarao et al. 2015; Yi 2016): DLD-1, CaCo-2, and HT-29, were chosen for testing their sensitivity to 5-FU applied in free and complex form (Fig. 8). Results showed a lack of toxic effect after treating CRC cells by 5 -FU when applied at concentration $5 \mu \mathrm{g} / \mathrm{mL}$. In turn, a fivefold increasing concentration of 5-FU caused depletion of the percentage of viable cells to 80\% in the case of DLD-1 and CaCo-2 cells and 55\% for HT-29 cells (Fig. 8C, F, I). Incubation of CRC cells with synthesized carriers without 5-FU exerted divergent effect dependently on treated

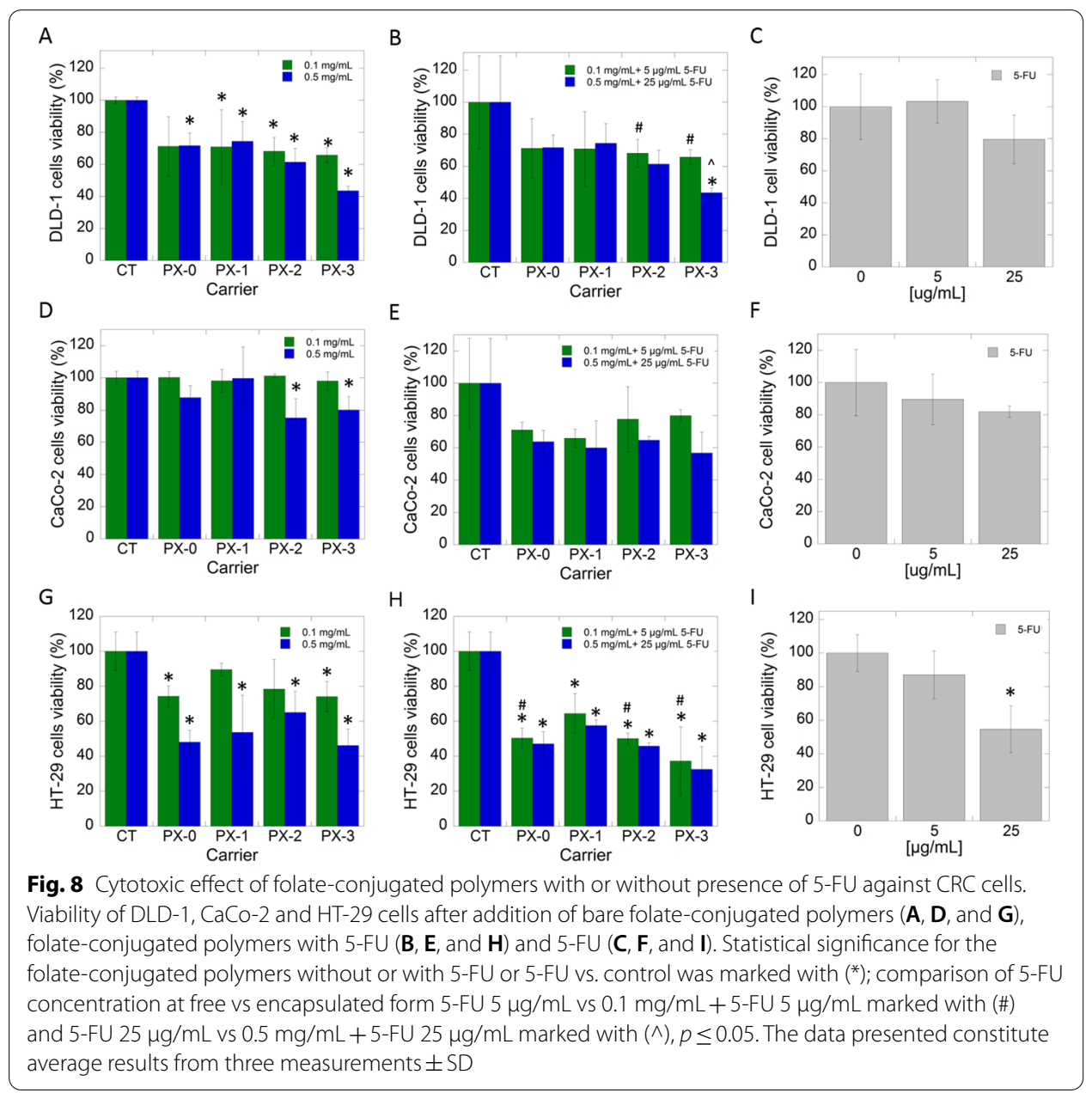


cells, which is probably associated with the difference in their molecular characteristics, including expression of specific genes and receptors (Bracht et al. 2010). In the case of DLD-1 cells, the addition of FA-decorated carriers caused a marked reduction of viable cells up to $60-70 \%$. In contrast, for carriers without FA moiety, viability around 95 and $75 \%$ for concentration 0.1 and $0.5 \mathrm{mg} / \mathrm{mL}$ has been noted (Fig. 8A). In turn, lack of significant impact on viability (percentage of viable cell $\sim 100 \%$ for carrier concentration $0.1 \mathrm{mg} / \mathrm{mL}$ and between 80 and $90 \%$ for carrier concentration $0.5 \mathrm{mg} / \mathrm{mL}$ ) of treated cells was observed in the case of CaCo-2 cells (Fig. 8D). Contrasting effect was noted in the case of HT-29 cells. The addition of carriers at concentration $0.1 \mathrm{mg} / \mathrm{mL}$ resulted in a decrease in the percentage of viable cells to $\sim 70 \%$, while the application of a higher dose- $0.5 \mathrm{mg} / \mathrm{mL}$ caused a significant depletion of viable cells up to $50 \%$ (Fig. 8G). Therefore, using these carriers as a platform for 5-FU delivery indicated a significant reduction of viable cells compared to treating them by 5 -FU in free form. In the case of DLD-1 and HT-29 cells, clear concentration and FA-dependent content have been observed (Fig. 8B, $\mathrm{H})$. At best, in the case of the complex of PX-3 and 5-FU, the reduction of HT-29 viable cells below $40 \%$ was noted. In turn, in the case of $\mathrm{CaCo}-2$ cells, incorporating 5 -FU into carriers network caused a decrease in the percentage of vital cells below $60 \%$, which is $30 \%$ lower than when cells were treated by 5 -FU in free form (Fig. 8E). Undoubtedly, the observed cytotoxic effect is more interesting due to the fact that the tested cells were not sensitive for 5-FU. However, the application of folate-conjugated polymers as components of combined therapy significantly increased its therapeutic efficiency. The major mechanisms causing development of cancer cells resistance to 5-FU treatment are based on impaired drug uptake and target alterations. Taking into account that 5-FU induces cytotoxicity either by interfering with biosynthesis of nucleic acids: RNA and DNA, we postulate that the application of synthesized FA-decorated polymeric carriers is helpful in overcoming the 5-FU resistance via interaction with FA receptors and providing drug uptake. It should be also pointed out that based on the published results, the divergence in the observed effect is probably dependent on the expression level of the folate receptors which is different in each of the tested cell lines (Soe et al. 2019; Doucette and Stevens 2001; Díaz-García et al. 2020). The aforementioned is justified due to the fact, that presence of folate moiety provide ease interaction with folate receptors on their surface and increase drug absorption in the colon area (Soe et al. 2019; Li et al. 2011). Moreover, currently several studies are going on to enhance the sensitivity of 5-FU in cancer cells and improve its therapeutic efficiency by the use of novel combination therapies such as encapsulated drugs (Sethy and Kundu 2021).

\section{Conclusions}

In the conclusion, we present synthesis of well-defined polymeric drug delivery systems (PDDS) based on PHEA- $b$-PNVCL. The application of HEA increases biocompatibility and enables folic acid incorporation to the system (via esterification reaction). We proved that systems with $100 \%$ of hydroxyl groups reacted with FA are not soluble in water so incorporation of lower amount of FA was essential. Thereby, three polymers with different amount of FA were produced and used for 5-FU incorporation via self-organization process. The results TEM show that obtained drugloaded polymers formed micelles, and their cloud point temperature was close to 
the temperature of the human body. All three polymers were biologically tested. Our results indicated that appropriately created carriers can be used as targets to develop complementary agents to limit the side effects of chemotherapy and improve the patients' quality of life. The aforementioned statement was established based on cytotoxic results, in which a significant decrease of the viability of the representatives of CRC cells has been noted. Moreover, we hypothesized that the presence of folic acid moiety provides not only targeted delivery, but also helps in drug uptake via endocytosis mediated by FA receptor interaction as well as protect the physiological cells before toxic effect of cytostatic agents. In effect, it could be concluded that the proposed carriers might be crucial in the further creation of specific carriers for the treatment of patients diagnosed with CRC, including those where drug-resistance phenotype has been confirmed. Additionally, the results obtained emphasize a huge potential associated with the application of folate-conjugated polymeric carriers and might create future directions in targeted anticancer therapy.

\begin{abstract}
Abbreviations
5-FU: 5-Fluorouracil; AIBN: 2,2'-Azobis(2-methylpropionitrile); ATCC: American Type Culture Collection; COX-2: Cyclooxygenase-2; CP: Cloud point; CRC: Colorectal cancer; CTA: Chain transfer agent; DLS: Dynamic Light Scattering; DMDMA: (2,2-Dimethyl-1,3-dioxolane-4-yl)methyl acrylate; dTMP: Deoxythymidine monophosphate; EGDA: Ethylene glycol diacrylate; FA: Folic acid; FBS: Fetal bovine serum; FdUMP: Fluorodeoxyuridine monophosphate; FR: Folic receptor; FT-IR: Fourier-transform infrared spectroscopy; IGF-1R: Insulin-like growth factor 1 receptor; LN2: Liquid nitrogen; MNP: Magnetic nanoparticles; MWCO: Molecular weight cut-off; NF-kB: Nuclear transcription factor; NIPAAm: N-Isopropylacrylamide; NMR: Nuclear Magnetic Resonance; NVCL: N-Vinylcaprolactam; PBS: Phosphate-buffered saline; PCL: Polycaprolactone; PE: Pentaerythritol; PEG: Poly(ethylene glycol); PHEA: Poly(2-hydroxyethyl acrylate); RAFT/MADIX: Reversible Addition-Fragmentation Chain Transfer/MAcromolecular Design via the Interchange of Xanthates; RBCs: Red Blood Cells; SEC: Size Exclusion Chromatography; TEM: Transmission Electron Microscope; TGA: ThermoGravimetric Analysis; TS: Thymidylate synthase; TTDDS: Tumor-Targeted Drug Delivery Systems; UV-Vis: Ultraviolet-Visible spectroscopy.
\end{abstract}

\title{
Supplementary Information
}

The online version contains supplementary material available at https://doi.org/10.1186/s12645-021-00104-9.

Additional file 1: Table S1. Synthesis details of the PHEA-b-PNVCL conjugation with folic acid. Figure S1. ${ }^{1} \mathrm{H}$ NMR spectrum of PX-4 in DMSO- $d_{6}$. Figure $\mathbf{S 2}$. $^{1} \mathrm{H}$ NMR spectrum of PHEA (DMSO- $d_{6}, 400 \mathrm{MHz}$ ). Figure $\mathbf{S 3}$. ' $\mathrm{H}$ NMR spectrum of PHEA-b-PNVCL (DMSO- $d_{6}, 400 \mathrm{MHz}$ ). Figure S4. FT IR spectra of PX-0, PX-1, PX-2, PX-3, PX-4, and folic acid. Figure S5. UV-Vis spectra of PX-0, PX-1, PX-2, PX-3, and PX-4 polymers. Figure S6. (A) The calibration curve of FA absorbance at $280 \mathrm{~nm}$ in distilled $\mathrm{H}_{2} \mathrm{O}$ vs. concentration and (B) calculations of exact folic acid content in polymers. Figure S7. (A) SEC-RI and (B) SEC-UV traces of PHEA-b-PVCL copolymer before and after post-modification with folic acid. Figure S8. (A) TGA and (B) DTG curves of FA, PHEA-b-PNVCL, and folate-conjugated polymers.

\section{Acknowledgements}

The authors are grateful to dr. Leszek Siergiejczyk (University of Bialystok) and dr. Jolanta Magnuszewska (University of Bialystok) for NMR analyses, to Mr. Sacha Ivanchenko (Paul Sabatier University Toulouse III) for SEC analyses, to Dr. Diana Sawicka (Medicinal Uniwersity of Bialystok) for help in cell culture preparation.

\section{Authors' contributions}

AZW provided the conception and plan of the study. ED made preliminary tests. GS carried out chemical experiments. KNL, SM, AS, and HC performed biological studies. GS, KHM, IMT, PM, and IK conducted instrumental analyzes. GS, KNL, KHM, IMT, and AZW CO-wrote the paper. All authors read and approved the final manuscript.

\section{Funding}

This work was financially supported by the National Science Centre, Poland, grant no. NCN/2016/21/B/ST5/01365 (AZW). Analyses were performed in the Centre of Synthesis and Analysis BioNanoTechno of the University of Bialystok. The equipment in the Centre was funded by the EU as a part of the Operational Program Development of Eastern Poland 2007-2013, projects: POPW.01.03.00-20-034/09-00 and POPW.01.03.00-20-004/11.

\section{Availability of data and materials}

All data used in this study are included in this published article (and Additional file 1). The datasets used are available from the corresponding authors on justified request. 


\section{Declarations}

\section{Ethics approval and consent to participate}

For the hemolysis assay, blood samples from healthy volunteers were collected based on ethical approval from the Institutional Review Board (IRB) of the Medical University of Bialystok (R-I-002/245/2019) and the donor's written informed consent.

\section{Consent for publication}

All authors consent to the publication of this work.

\section{Competing interests}

The authors declare that they have no competing interests.

\section{Author details}

${ }^{1}$ Faculty of Chemistry, University of Bialystok, Ciolkowskiego 1K, 15-245 Bialystok, Poland. ${ }^{2}$ Department of Experimental Pharmacology, Medical University of Bialystok, Szpitalna 37, 15-361 Bialystok, Poland. ${ }^{3}$ Doctoral School, Medical University of Bialystok, Kilinskiego 1, 15-089 Bialystok, Poland. ${ }^{4}$ Doctoral School of Exact and Natural Sciences, University of Bialystok, Ciolkowskiego 1K, 15-245 Bialystok, Poland.

Received: 29 July 2021 Accepted: 1 November 2021

Published online: 18 November 2021

\section{References}

Alvarez-Lorenzo C (2014) Smart drug delivery systems: from fundamentals to the clinic. Chem Commun 50(58):7743-7765

Beija M, Marty J-D, Destarac M (2011) Thermoresponsive poly(N-vinyl caprolactam)-coated gold nanoparticles: sharp reversible response and easy tunability. Chem Commun 47(10):2826

Biju S, Gallo J, Bañobre-López M, Manshian BB, Soenen SJ, Himmelreich U et al (2018) A magnetic chameleon: biocompatible lanthanide fluoride nanoparticles with magnetic field dependent tunable contrast properties as a versatile contrast agent for low to ultrahigh field mri and optical imaging in biological window. Chem Eur J 24(29):7388-7397

Bracht K, Nicholls AM, Liu Y, Bodmer WF (2010) 5-Fluorouracil response in a large panel of colorectal cancer cell lines is associated with mismatch repair deficiency. Br J Cancer 103(3):340-346

Bray F, Ferlay J, Soerjomataram I, Siegel RL, Torre LA, Jemal A (2018) Global cancer statistics 2018: GLOBOCAN estimates of incidence and mortality worldwide for 36 cancers in 185 countries. CA Cancer J Clin 68(6):394-424

Camaro C, Danse PW, Bosker HA (2009) Acute chest pain in a patient treated with capecitabine. Neth Heart J 17(7):288-291

Chaturvedi S, Lal S, Sen P, Mishra AK (2018) Synthesis, docking, and preliminary in vitro/in vivo evaluation of MPP-dithiocarbamate-capped silver nanoparticle as dual-imaging agent for $5 \mathrm{HT}_{1 \mathrm{~A}}$. Int J Nanomedicine 13:19-23

Cortez-Lemus NA, Licea-Claverie A (2016) Poly(N-vinylcaprolactam), a comprehensive review on a thermoresponsive polymer becoming popular. Prog Polym Sci 53:1-51

Cui Y, Jiang X, Feng C, Gu G, Xu J, Huang X (2016) First double hydrophilic graft copolymer bearing a poly(2-hydroxylethyl acrylate) backbone synthesized by sequential RAFT polymerization and SET-LRP. Polym Chem 7(18):3156-3164

Díaz-García D, Montalbán-Hernández K, Mena-Palomo I, Achimas-Cadariu P, Rodríguez-Diéguez A, López-Collazo E et al (2020) Role of folic acid in the therapeutic action of nanostructured porous silica functionalized with organotin(IV) compounds against different cancer cell lines. Pharmaceutics 12(6):512

Doucette MM, Stevens VL (2001) Folate receptor function is regulated in response to different cellular growth rates in cultured mammalian cells. J Nutr 131(11):2819-2825

Eliezar J, Scarano W, Boase NRB, Thurecht KJ, Stenzel MH (2015) In vivo evaluation of folate decorated cross-linked micelles for the delivery of platinum anticancer drugs. Biomacromol 16(2):515-523

Farhat A, Malecki E, Bonaterra GA, Röthlein D, Wolf M, Schmitt J et al (2014) Cytostatic/cytotoxic effects of 5-fluorouridine nucleolipids on colon, hepatocellular, and renal carcinoma cells: in vitro identification of a potential cytotoxic multianticancer drug. Chem Biodivers 11(3):469-482

Fernández M, Javaid F, Chudasama V (2018) Advances in targeting the folate receptor in the treatment/imaging of cancers. Chem Sci 9(4):790-810

Hazrati MK, Hadipour NL (2016) Adsorption behavior of 5-fluorouracil on pristine, B-, Si-, and Al-doped C60 fullerenes: a first-principles study. Phys Lett A 380(7-8):937-941

Jeong J, Kim Y-J, Lee DY, Sohn K-Y, Yoon SY, Kim JW (2019) Mitigating effect of 1-palmitoyl-2-linoleoyl-3-acetyl-rac-glycerol (PLAG) on a murine model of 5-fluorouracil-induced hematological toxicity. Cancers 11(11):1811

Jiang X, Lu G, Feng C, Li Y, Huang X (2013a) Poly(acrylic acid)-graft-poly(N-vinylcaprolactam): a novel pH and thermo dual-stimuli responsive system. Polym Chem 4(13):3876

Jiang X, Li Y, Lu G, Huang X (2013b) A novel poly(N-vinylcaprolactam)-based well-defined amphiphilic graft copolymer synthesized by successive RAFT and ATRP. Polym Chem 4(5):1402-1411

Kermagoret A, Fustin C-A, Bourguignon M, Detrembleur C, Jérôme C, Debuigne A (2013) One-pot controlled synthesis of double thermoresponsive N-vinylcaprolactam-based copolymers with tunable LCSTs. Polym Chem 4(8):2575

Large DE, Soucy JR, Hebert J, Auguste DT (2019) Advances in receptor-mediated, tumor-targeted drug delivery. Adv Ther 2(1):1800091

Lestuzzi C, Vaccher E, Talamini R, Lleshi A, Meneguzzo N, Viel E et al (2014) Effort myocardial ischemia during chemotherapy with 5-fluorouracil: an underestimated risk. Ann Oncol 25(5):1059-1064 
Li P, Wang Y, Zeng F, Chen L, Peng Z, Kong LX (2011) Synthesis and characterization of folate conjugated chitosan and cellular uptake of its nanoparticles in HT-29 cells. Carbohydr Res 346(6):801-806

Longley DB, Harkin DP, Johnston PG (2003) 5-Fluorouracil: mechanisms of action and clinical strategies. Nat Rev Cancer 3(5):330-338

Louage B, Zhang Q, Vanparijs N, Voorhaar L, Vande Casteele S, Shi Y et al (2015) Degradable ketal-based block copolymer nanoparticles for anticancer drug delivery: a systematic evaluation. Biomacromol 16(1):336-350

Mandal A, Cholkar K, Mandal A (2017) Chapter 4-diagnosis and drug delivery to the brain: novel strategies. emerging nanotechnologies for diagnostics, drug delivery and medical devices. Elsevier, Boston, pp 59-83

Marchetti C, Giorgini M, De Medici C, Palaia I, ladarola R, Vertechy L et al (2014) Targeted drug delivery via folate receptors in recurrent ovarian cancer: a review. OncoTargets Ther. 7:1223

Misiak P, Niemirowicz-Laskowska K, Markiewicz KH, Misztalewska-Turkowicz I, Wielgat P, Kurowska I et al (2020) Evaluation of cytotoxic effect of cholesterol end-capped poly(N-Isopropylacrylamide)s on selected normal and neoplastic cells. Int J Nanomedicine 15:7263-7278

Narmani A, Rezvani M, Farhood B, Darkhor P, Mohammadnejad J, Amini B et al (2019) Folic acid functionalized nanoparticles as pharmaceutical carriers in drug delivery systems. Drug Dev Res 80(4):404-424

Niemirowicz K, Car H, Sadowska A, Wątek M, Krętowski R, Cechowska-Pasko M et al (2017) Pharmacokinetics and anticancer activity of folic acid-functionalized magnetic nanoparticles. J Biomed Nanotechnol 13(6):665-677

Ouyang W, Liu Y, Deng D, Zhou F, Xie C (2018) The change in peripheral blood monocyte count: a predictor to make the management of chemotherapy-induced neutropenia. J Cancer Res Ther 14(10):565

Panja S, Dey G, Bharti R, Kumari K, Maiti TK, Mandal M et al (2016) Tailor-made temperature-sensitive micelle for targeted and on-demand release of anticancer drugs. ACS Appl Mater Interfaces 8(19):12063-12074

Patysheva M, Stakheyeva M, Larionova I, Fedorov A, Kzhyshkowska J, Cherdyntseva N (2019) Cytostatic cancer therapy modulates monocyte-macrophage cell functions: how it impacts on treatment outcomes. Exp Oncol 41(3):248-253

Prabaharan M, Grailer JJ, Steeber DA, Gong S (2009) Thermosensitive micelles based on folate-conjugated poly( $\mathrm{N}$-vinylcaprolactam)-block-poly(ethylene glycol) for tumor-targeted drug delivery. Macromol Biosci 9(8):744-753

Sala RL, Kwon MY, Kim M, Gullbrand SE, Henning EA, Mauck RL et al (2017) Thermosensitive poly(N-vinylcaprolactam) injectable hydrogels for cartilage tissue engineering. Tissue Eng Part A 23(17-18):935-945

Sandvei P, Nordhagen R, Michaelsen TE, Wolthuis K (1987) Fluorouracil (5-FU) induced acute immune haemolytic anaemia. Br J Haematol 65(3):357-359

Sara JD, Kaur J, Khodadadi R, Rehman M, Lobo R, Chakrabarti S et al (2018) 5-fluorouracil and cardiotoxicity: a review. Ther Adv Med Oncol 10:175883591878014

Sethy C, Kundu CN (2021) 5-Fluorouracil (5-FU) resistance and the new strategy to enhance the sensitivity against cancer: Implication of DNA repair inhibition. Biomed Pharmacother 137:111285

Siirilä J, Häkkinen S, Tenhu H (2019) The emulsion polymerization induced self-assembly of a thermoresponsive polymer poly( N -vinylcaprolactam). Polym Chem 10(6):766-775

Soares PMG, Mota JMSC, Gomes AS, Oliveira RB, Assreuy AMS, Brito GAC et al (2008) Gastrointestinal dysmotility in 5-fluorouracil-induced intestinal mucositis outlasts inflammatory process resolution. Cancer Chemother Pharmacol 63(1):91-98

Soe ZC, Poudel BK, Nguyen HT, Thapa RK, Ou W, Gautam M et al (2019) Folate-targeted nanostructured chitosan/chondroitin sulfate complex carriers for enhanced delivery of bortezomib to colorectal cancer cells. Asian J Pharm Sci 14(1):40-51

Soleymani J, Hasanzadeh M, Shadjou N, Somi MH, Jouyban A (2020) The role of nanomaterials on the cancer cells sensing based on folate receptor: analytical approach. TrAC Trends Anal Chem 125:115834

Sonis ST, Elting LS, Keefe D, Peterson DE, Schubert M, Hauer-Jensen M et al (2004) Perspectives on cancer therapyinduced mucosal injury: pathogenesis, measurement, epidemiology, and consequences for patients. Cancer 100(S9):1995-2025

Srinivasarao M, Galliford CV, Low PS (2015) Principles in the design of ligand-targeted cancer therapeutics and imaging agents. Nat Rev Drug Discov 14(3):203-219

Steinhauer W, Hoogenboom R, Keul H, Moeller M (2010) Copolymerization of 2-hydroxyethyl acrylate and 2-methoxyethyl acrylate via RAFT: kinetics and thermoresponsive properties. Macromolecules 43(17):7041-7047

Tan S, Wong EHH, Fu Q, Ren JM, Sulistio A, Ladewig K et al (2014) Azobenzene-functionalised core cross-linked star polymers and their host-guest interactions. Aust J Chem 67(1):173

Taton D, Wilczewska AZ, Destarac M (2001) The chain transfer agent was synthesized using a literature-based procedure. Macromol Rapid Commun 22:1497-1503

Totea G, Ionita D, Demetrescu I, Mitache M (2014) In vitro hemocompatibility and corrosion behavior of new Zr-binary alloys in whole human blood. Open Chem 12(7):796-803

VanderVeen BN, Sougiannis AT, Velazquez KT, Carson JA, Fan D, Murphy EA (2020) The acute effects of 5 fluorouracil on skeletal muscle resident and infiltrating immune cells in mice. Front Physiol 11:593468

Vargün E, Usanmaz A (2005) Polymerization of 2-hydroxyethyl acrylate in bulk and solution by chemical initiator and by ATRP method. J Polym Sci Part Polym Chem 43(17):3957-3965

Vodenkova S, Buchler T, Cervena K, Veskrnova V, Vodicka P, Vymetalkova V (2020) 5-fluorouracil and other fluoropyrimidines in colorectal cancer: past, present and future. Pharmacol Ther 206:107447

Vora A, Riga A, Dollimore D, Alexander KS (2002) Thermal stability of folic acid. Thermochim Acta 392-393:209-220

Wei Y, Yang P, Cao S, Zhao L (2018) The combination of curcumin and 5-fluorouracil in cancer therapy. Arch Pharm Res 41(1):1-13

Witek P, Korga A, Burdan F, Ostrowska M, Nosowska B, Iwan M et al (2016) The effect of a number of H9C2 rat cardiomyocytes passage on repeatability of cytotoxicity study results. Cytotechnology 68(6):2407-2415

Yi Y-S (2016) Folate receptor-targeted diagnostics and therapeutics for inflammatory diseases. Immune Netw 16(6):337

Yoo J, Park C, Yi G, Lee D, Koo H (2019) Active targeting strategies using biological ligands for nanoparticle drug delivery systems. Cancers 11(5):640 
Yu B, Tai HC, Xue W, Lee LJ, Lee RJ (2010) Receptor-targeted nanocarriers for therapeutic delivery to cancer. Mol Membr Biol 27(7):286-298

Zhang N, Yin Y, Xu S-J, Chen W-S (2008) 5-Fluorouracil: mechanisms of resistance and reversal strategies. Molecules 13(8):1551-1569

Zhang Q-Y, Wang F-X, Jia K-K, Kong L-D (2018) Natural product interventions for chemotherapy and radiotherapyinduced side effects. Front Pharmacol 9:1253

Zhao X, Li H, Lee RJ (2008) Targeted drug delivery via folate receptors. Expert Opin Drug Deliv 5(3):309-319

Zhao X, Coutelier O, Nguyen HH, Delmas C, Destarac M, Marty J-D (2015) Effect of copolymer composition of RAFT/ MADIX-derived N-vinylcaprolactam/N-vinylpyrrolidone statistical copolymers on their thermoresponsive behavior and hydrogel properties. Polym Chem 6(29):5233-5243

Zheng H-C (2017) The molecular mechanisms of chemoresistance in cancers. Oncotarget 8(35):59950-59964

\section{Publisher's Note}

Springer Nature remains neutral with regard to jurisdictional claims in published maps and institutional affiliations.

- fast, convenient online submission

- thorough peer review by experienced researchers in your field

- rapid publication on acceptance

- support for research data, including large and complex data types

- gold Open Access which fosters wider collaboration and increased citations

- maximum visibility for your research: over 100M website views per year

At BMC, research is always in progress.

Learn more biomedcentral.com/submissions 